September 2004 • NREL/TP-500-31486

\title{
Preliminary Structural Design of Composite Blades for Two- and Three-Blade Rotors
}

\author{
G. Bir and P. Migliore
}

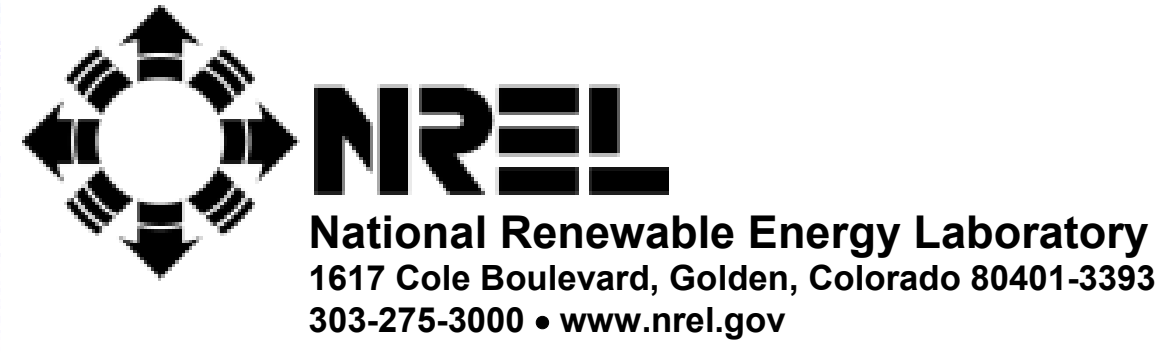

Operated for the U.S. Department of Energy Office of Energy Efficiency and Renewable Energy by Midwest Research Institute • Battelle 


\section{Preliminary Structural Design of Composite Blades for Two- and Three-Blade Rotors}

\section{G. Bir and P. Migliore}

Prepared under WER4.3303

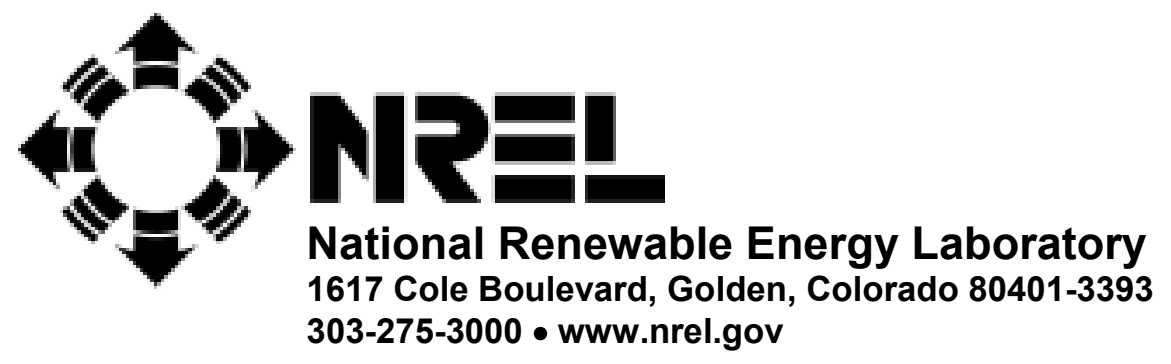

Operated for the U.S. Department of Energy Office of Energy Efficiency and Renewable Energy

by Midwest Research Institute • Battelle

Contract No. DE-AC36-99-G010337 


\section{NOTICE}

This report was prepared as an account of work sponsored by an agency of the United States government. Neither the United States government nor any agency thereof, nor any of their employees, makes any warranty, express or implied, or assumes any legal liability or responsibility for the accuracy, completeness, or usefulness of any information, apparatus, product, or process disclosed, or represents that its use would not infringe privately owned rights. Reference herein to any specific commercial product, process, or service by trade name, trademark, manufacturer, or otherwise does not necessarily constitute or imply its endorsement, recommendation, or favoring by the United States government or any agency thereof. The views and opinions of authors expressed herein do not necessarily state or reflect those of the United States government or any agency thereof.

Available electronically at http://www.osti.gov/bridge

Available for a processing fee to U.S. Department of Energy and its contractors, in paper, from:

U.S. Department of Energy

Office of Scientific and Technical Information

P.O. Box 62

Oak Ridge, TN 37831-0062

phone: 865.576.8401

fax: 865.576.5728

email: mailto:reports@adonis.osti.gov

Available for sale to the public, in paper, from:

U.S. Department of Commerce

National Technical Information Service

5285 Port Royal Road

Springfield, VA 22161

phone: 800.553 .6847

fax: 703.605.6900

email: orders@ntis.fedworld.gov

online ordering: http://www.ntis.gov/ordering.htm 


\section{Executive Summary}

A computerized method has been developed to aid in the preliminary design of composite wind turbine blades. The method allows for arbitrary specification of the chord, twist, and airfoil geometry along the blade and an arbitrary number of shear webs. Given the blade external geometry description and its design load distribution, the Fortran code uses ultimate-strength and buckling-resistance criteria to compute the design thickness of load-bearing composite laminates. The code also includes an analysis option to obtain blade properties if a composite laminates schedule is prescribed. These properties include bending stiffness, torsion stiffness, mass, moments of inertia, elastic-axis offset, and center-of-mass offset along the blade. Nonstructural materials - gelcoat, nexus, and bonding adhesive - are also included for computation of mass. The code includes an option to format the output properties that can be directly input to advanced aeroelastic codes. This report summarizes the structural layout of composite laminates within the blade, the design approach, and the computational process. Finally, we present the results of two composite blades designed using this code in support of a project covering comparison of two- and three-blade rotors for a hypothetical turbine. 


\section{Nomenclature for Tables 2-5}

$$
\begin{aligned}
& \operatorname{rad}=\text { distance from the blade root } \\
& \operatorname{mxx}=\text { flap bending moment at a section } \\
& \mathrm{db}=\text { double-bias composite material } \\
& \text { uni }=\text { unidirectional composite material } \\
& \mathrm{tdb}=\text { thickness of the } \mathrm{db} \text { material } \\
& \mathrm{tdb} \_\mathrm{n} \quad=\text { thickness of the } \mathrm{db} \text { material that allows integer number of plies } \\
& \text { n_db }=\text { number of db-material plies } \\
& \text { tecore }=\text { thickness of core at trailing-edge section } \\
& \text { tecore_ } \mathrm{n}=\text { thickness of the trailing-edge core that allows integer number of plies } \\
& \text { n_tecore }=\text { number of core-material plies } \\
& \text { tuni }=\text { thickness of the uni material } \\
& \text { tuni_n } \quad=\text { thickness of the uni material allows integer number of plies } \\
& \text { n_uni }=\text { number of uni-material plies } \\
& \text { t_midcr }=\text { thickness of the core at the mid-section allows integer number of plies } \\
& \text { t_le = total thickness at the leading edge } \\
& \text { t_mid = total thickness of the midsection } \\
& \text { t_te }=\text { total thickness at the trailing edge } \\
& \text { id_fail }=\text { failure identifier (1:db material fails first; uni material fails first) } \\
& \text { no_iter }=\text { number of iterations to convergence } \\
& \text { tuni-1 = uni thickness modified for gradual ply drop and uni-root-attachment } \\
& \mathrm{tdb}-1=\mathrm{db} \text { thickness modified for gradual ply drop and uni-root-attachment } \\
& \text { tuni-2 = uni thickness modified for gradual ply drop and db-root-attachment } \\
& \text { tdb-2 = db thickness modified for gradual ply drop and db-root-attachment } \\
& \text { te_core }=\text { trailing-section core thickness modified for gradual ply drop } \\
& \text { t_mid_cr }=\text { midsection core thickness modified for gradual ply drop } \\
& \text { mass }=\text { mass per unit length along blade span } \\
& \text { imyy = lag mass mom of inertia per unit length } \\
& \operatorname{imxx}=\text { flap mass mom of inertia per unit length } \\
& x_{-} \text {cg }=\text { c.g. offset from reference axis } \\
& \mathrm{x} \_\mathrm{ea} \quad=\text { elastic-axis offset from reference axis } \\
& \text { gj } \quad=\text { torsional stiffness } \\
& \text { eaxial }=\text { axial stiffness } \\
& \text { ei_lag = lag bending stiffness } \\
& \text { ei_flap = flap bending stiffness }
\end{aligned}
$$




\section{Table of Contents}

Table of Contents _

Table of Figures __

Table of Tables

1. Introduction 1

2. Blade Structural Layout __ 2

3. Technical Approach _ 2

Blade Design __ 2

Computation of Structural Properties __ 6

4. Code Usage Steps

i) Specification of Blade External Geometry ___ 6

ii) Selection of Materials _ _ 7

iii) Specification of Extreme Load Distribution __ 7

iv) Preparation of Main and Auxiliary Input Files __ 7

v) Running the Code for Blade Design___ 11

vi) Examination/Streamlining of Design 12

vii) Running the Code for Computation of Blade Properties __ 12

Design values output by the code___ 13

Modified design values ___ 13

Design values output by the code ___ 14

Modified design values ___ 14

5. Code Verification

6. Results: Design of Blades for Two- and Three-Bladed Rotors

7. Comments and Future Work

Acknowledgments

References 30

\section{Table of Figures}

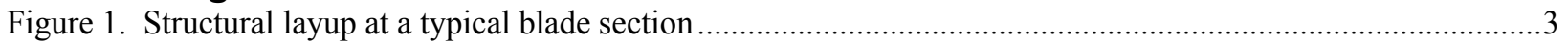

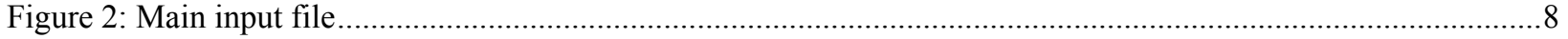

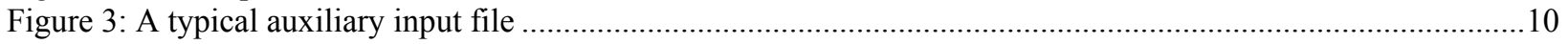

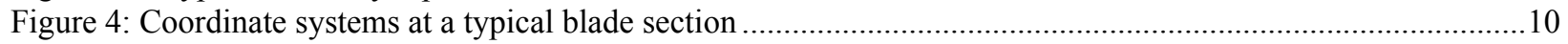

Figure 5: Variation of airfoil geometry along the blade ............................................................................ 19

Figure 6a: Bending-moment, chord, and twist distribution along the B2 blade ............................................20

Figure 6b: Bending-moment, chord, and twist distribution along the B3 blade .................................................21

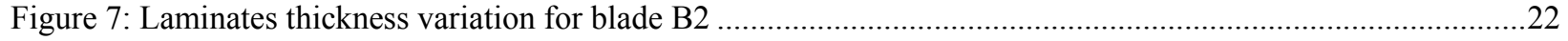

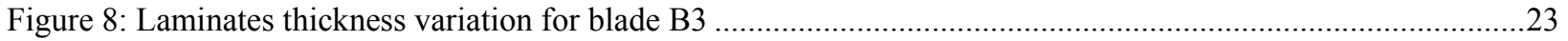

Figure 9: Spanwise variation of stiffness properties for blade B2 .............................................................24

Figure 10: Variation of section inertia, center-of-mass location, and elastic-axis location along blade B2 ..............25

Figure 11: Spanwise variation of stiffness properties for blade B3 .............................................................26

Figure 12: Variation of section inertia, center-of-mass location, and elastic-axis location along blade B3 ..............27

\section{Table of Tables}

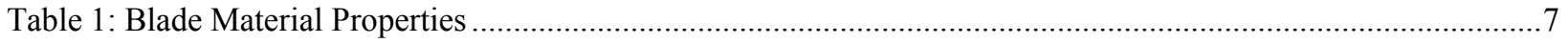

Table 2. Laminate Thickness Requirements at Various Sections (Blade B2) ..................................................13

Table 3. Laminate Thickness Requirements at Various Sections (Blade B3).......................................................14

Table 4a. Blade B2 Structural Properties (Double-Bias-Material Root Attachment) ................................................28

Table 4b. Blade B2 Structural Properties (Unidirectional-Material Root Attachment) ..........................................28

Table 5a. Blade B3 Structural Properties (Double-Bias-Material Root Attachment) ............................................29

Table 5b. Blade B3 Structural Properties (Unidirectional-Material Root Attachment) ........................................29 


\section{Introduction}

A blade structural design code was developed in support of a project comparing two- and three-blade rotors for a hypothetical turbine. The code generated blade designs and their structural properties. Based on these properties, we built aeroelastic models of two- and three-blade rotors for comparative studies. The theory basis for the blade design code, which uses the classical laminate theory, has already been reported [1]. This report describes blade structural layout, a summary of the theory basis, and the steps required for code usage. Finally, we describe the code-generated composite blade designs used in the comparative study.

The code allows for arbitrary specification of the chord, twist, and airfoil geometry along the blade and an arbitrary number of shear webs. Given the blade's external geometry description and its design load distribution, the code uses ultimate-strength and buckling-resistance criteria to compute the design thickness of load-bearing composite laminates. The code also includes an analysis option to obtain blade properties if a composite laminate schedule is prescribed. These properties include bending stiffness, torsion stiffness, mass, moments of inertia, elastic-axis offset, and center-of-mass offset along the blade. The Fortran code also includes an option to format the output properties that can be directly input to advanced aeroelastic codes.

We could have used a finite-element approach to design the blades; however, that approach is timeconsuming, tedious, and requires special expertise. Moreover, it is an analysis tool, rather than a design tool, and needs to be used interactively and repeatedly. At each step, the user changes the laminate schedule, rebuilds the model, and surveys the stress field until the design criteria are met. Also, we must use three-dimensional elements because conventional one-dimensional elements would provide the same results as our code. Three-dimensional elements account for warping and shear effects ignored by the classical laminate theory. For slender, closed-section blades, in which such effects may be negligible, and for preliminary design, in which large safety factors account for uncertainties, a finite-element approach is probably not warranted. Efforts are underway to facilitate the application of finite-element modeling to the design of a wind turbine blade [2]. Our goal, however, is to obtain a rapid estimate of blade properties that yield a reasonably accurate dynamic blade model. Therefore, we developed a computerized tool that requires only modest skill levels and that produces rapid design calculations without any user interaction. Also, the code may be used as a front-end design estimator for more refined design tools like the NuMAD [3].

This report is divided into seven sections. Section 2 describes the structural layout of composite materials within the blade. This layout accommodates a general multi-cell blade cross section, with box- and Dspars as special cases. Section 3 summarizes the technical approach covering blade design and computation of its structural properties. The design approach, though simple, is novel; it is based on formulations that express the design criteria analytically in terms of the thickness of laminates. This allows extremely fast and automated design computations without user interaction. Section 4 outlines the seven steps for designing and analyzing the blade. Section 5 provides a brief description of the code verification efforts. Section 6 describes the application of the code to the design and analysis results of the two blades used in the aforementioned comparative study. The design was carried out using a static load distribution corresponding to IEC Class 2 50-year extreme wind [4]. Although this represents a severe load and is often adequate for a preliminary design, it is not always the governing case for blade structural design. Fatigue concerns may dominate. Fatigue loads are dependent on the structural dynamics of the whole turbine, though, and are rarely known in the early stages of preliminary design. However, if fatigue loads are known, the code may be used to provide stress-time histories at desired locations on the blade. These stress histories may then be post-processed to provide the fatigue life. Unlike the ultimate strength and the buckling criteria, the code has no direct provision for fatigue criterion that can be analytically satisfied. Section 7 offers comments and suggestions for future work. 


\section{Blade Structural Layout}

Figure 1 shows the assumed structural layout of composite materials within a typical blade cross section. The figure shows a three-cell blade section with two webs, but the code is applicable to a multi-cell section with an arbitrary number of webs. The outermost skin of a section consists of three layers: a gelcoat layer, a nexus layer, and a double-bias-material composite laminate. In this report, we define a laminate as a stack of plies, where a ply is a planar composite mat. The gelcoat outer layer provides a smooth surface, and although it is not a structural material, it can significantly contribute to the blade mass. Nexus is a soft-material mat that shields the rough surface of the underlying double-bias laminate and provides a relatively smooth but absorbent surface for the gelcoat. At the blade trailing edge, the double-bias laminate splits into two layers to accommodate a core material, such as balsa, foam, or honeycomb, as shown in detail CC of Figure 1. The core-material laminate augments the buckling strength of the trailing section of the blade.

A composite box-spar is contained in the midsection of the blade and is attached to the skin double-bias layers at its upper and lower surfaces. The box-spar divides the blade interior into three cells, with the box-spar forming the mid-cell. A lining, typically a double-bias layer, covers the inside surface of each cell. As shown in detail BB, the box-spar is made of unidirectional composite laminates with an embedded core material. Because of its good axial load-bearing capabilities, the unidirectional laminate provides most of the bending strength. The core material provides the buckling strength to the mid-cell. The two vertical sides of the box-spar serve as webs. Detail AA of Figure 1 shows the sequence of composite layers in each web.

Whereas the primary function of the unidirectional layers is to provide flexural strength, the functions of the double-bias layers are to provide shear strength and to prevent splaying of the unidirectional material. Computational effort is minimized by assuming that all double-bias plies are stacked in one laminate and all unidirectional plies are stacked in another laminate (BB in Figure 1). In reality, the double-bias and unidirectional plies may be interspersed to form a single laminate. This interspersing of plies may have a significant effect on the blade structural integrity at the micro level. However, it will have little effect on the blade strength and properties predicted by the code, assuming the thickness of the combined stack is much smaller than the overall blade thickness, which usually is the case.

Figure 1 shows a box-spar configuration, which we used for our studies. A D-spar configuration may be obtained by simply moving the forward web to the leading-edge location, where its height automatically becomes zero. Depending on the loading environment and manufacturing considerations, a designer may opt for structural layouts different from the one shown in Figure 1. For example, for the webs, the designer might replace the unidirectional laminates with double-bias laminates, which provide higher shear strength. Some blade designs show the upper- and lower-surface unidirectional laminates extended somewhat beyond the web locations. Currently, we are surveying construction details of a few blades and consulting with blade designers to identify candidate layouts that are most likely to be used. We may extend our code to accommodate the additional layouts.

\section{Technical Approach}

\section{Blade Design}

The design objective is to size the thickness of the unidirectional laminate, double-bias laminate, and core material so that the blade has minimum weight and remains fail-safe under the extreme load distribution. For a conservative design, we assume that the gelcoat and the nexus are not load-bearing materials and, therefore, are not sized. The design is carried out using the ultimate strength criterion, the buckling strength criterion, and two trend-based relations [1]; a summary is provided below.

The blade is assumed straight, tapered, and twisted about the $z$-axis, which we call the reference axis. A local dextral frame $(x, y, z)$ is attached to each blade cross section such that the $z$-axis coincides with the 

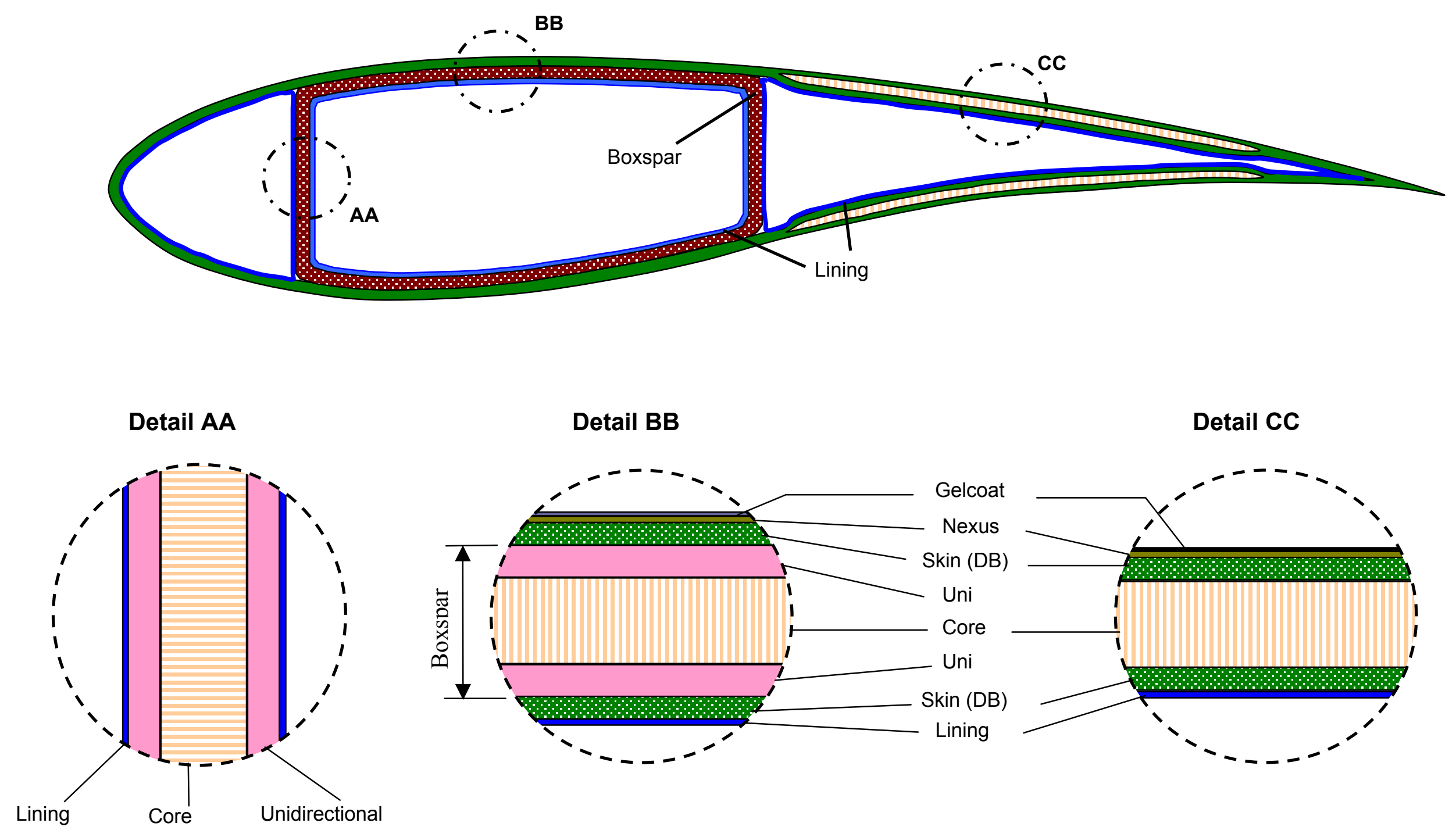

Figure 1. Structural layup at a typical blade section 
blade reference $Z$-axis and is directed toward the blade tip. The $x$-axis coincides with the chord and is directed toward the section leading edge. The ultimate strength criterion is:

$$
-M_{x} E(x, y) \frac{\bar{T}_{y}\left(y-y_{e}\right)-\bar{T}_{x y}\left(x-x_{e}\right)}{\bar{T}_{x} \bar{T}_{y}-\left(\bar{T}_{x y}\right)^{2}} \leq \sigma_{z z}(x, y)
$$

It states that the axial stress at any point $(x, y)$ of the blade section at $z$, given by the left side of the equation, does not exceed the allowable design stress, $\sigma_{z z}(x, y)$, for the material at that point. The allowable design stress for the material is its ultimate strength, compressive or tensile, multiplied by a factor of safety. The other quantities appearing in Equation (1) are defined as follows:

$$
\begin{aligned}
& \bar{T}_{x y}=\bar{E} \bar{I}_{x y}-S_{x} S_{y} / \overline{E A} \\
& \bar{T}_{x}=\bar{E} \bar{I}_{x}-S_{x}{ }^{2} / \overline{E A} \\
& \bar{T}_{y}=\bar{E}_{y}-S_{y}{ }^{2} / \overline{E A} \\
& x_{e}=S_{y} / \overline{E A} \\
& y_{e}=S_{x} / \overline{E A}
\end{aligned}
$$

$M_{x}$ is the flap bending moment about the x-axis; $E(x, y)$ is the Young's modulus of the composite material at point $(x, y) ; E I_{x}, E I_{y}$, and $E I_{x y}$ are the effective direct- and cross-flexural-stiffness values with respect to the $x$ - and $y$-axes; and $S_{x}$ and $S_{y}$ are the elastic first moments of inertia about the $x$ - and $y$-axes. To compute these elasticity-related quantities, we discretize the blade-section periphery into a number of area segments. Each area segment consists of a stack of composite plies. A typical area segment for the blade skin, for example, would include unidirectional plies sandwiched between double-bias plies. We compute the distance and orientation of each segment composite ply with respect to the $x$ - and $y$-axes and use this to determine the ply contribution to the flexural stiffness. Contribution of all plies is added to yield the effective flexural stiffness. All stiffness values are nonlinear functions of the double-bias laminate thickness that is known and the unidirectional laminate thickness that is to be determined. We set $\sigma_{z z}$ equal to the compressive or tensile allowable design stress value depending on whether it is negative or positive. Then we used a Newton-Raphson scheme to solve Equation (1) and obtain the required unidirectional laminate thickness. When computing the effective flexural stiffness, we do not include the gelcoat and the nexus layers because their contribution to strength is negligible. However, we do include the inertia contribution of these layers in computing the blade properties.

The buckling criterion is:

$$
\int_{\text {panel-bottom }}^{\text {panel-top }} \sigma(z, \zeta, \tau) d \tau \leq 3.6 * \frac{\pi^{2}}{b^{2}} \int_{\text {panel-bottom }}^{\text {panel-top }} \frac{E(z, \zeta, \tau) \tau^{2}}{\left[1-\left(v(z, \zeta, \tau)^{2}\right)\right]} d \tau
$$

This states that the edge loading per unit peripheral length of a blade surface panel does not exceed the Euler buckling load for that panel. The left side of this equation expresses the edge loading per unit peripheral length of a blade surface panel, and it is obtained by integrating the axial compressive stresses over the thickness of a panel. The longitudinal $z$-axis is directed toward the blade tip, and the $\zeta$ - and $\tau$ axes form the mid-surface of the panel. The $\tau$ represents the distance of a material point in the panel from the $z-\zeta$ neutral surface. The right side of Equation 2 represents the critical buckling load of the panel (note that it is proportional to the panel flexural rigidity represented by the integral term on the right-hand side). 
$E$ is the effective Young's modulus in the longitudinal $z$ direction and $v$ is the Poison's ratio at the point $(z, \zeta, \tau)$.

We apply the buckling criterion to the blade upper surface panels, which usually are in compression under the extreme loading conditions. These consist of panels bounded by webs and the trailing-edge panel enclosed between the aft-web and the trailing edge. We assume that the highly curved and short-length leading-edge panel remain buckle-free. Also, for a conservative buckling analysis, we assume the edges of each panel parallel to the $z$-axis are simply supported, and the edges perpendicular to the $z$-axis are free. In reality, all edges would have a finite restraint to rotation due to the adjoining panels, and the buckling resistance would be somewhat enhanced. Also, to keep the analysis simple, we ignore the nonlinear geometric and inelastic effects.

Compared to unidirectional-material, the double-bias material usually offers a much lower stiffness along the blade. The ultimate-strength criterion would, therefore, dictate that only the unidirectional material be used, resulting in a zero-thickness requirement for the double-bias material. Though the double-bias material does contribute to flexural rigidity, its primary role is to prevent splaying of the unidirectional plies, to provide resistance to accidental denting of the blade surface, and to provide shear strength. Because of the low torsion loads likely to be encountered by a typical wind turbine blade, the shearstrength criteria may not yield any requirement for the double-bias material. A rigorous relation governing double-bias material requirements for splay prevention and dent resistance is not available. We, therefore, consulted blade designers and manufacturers, and their input helped us formulate the following simple relation to compute the double-bias laminate thickness:

$$
t_{d b}=\max \left[m_{-} \text {ratio } * \max \left(w_{\text {panel-1}}, w_{\text {panel-2 }}, \cdots, w_{\text {panel-n}}\right), m_{-} d b^{*} t_{d b-p l y}\right]
$$

Here $w_{\text {panel- } i}$ is the width of panel $i$ between webs $i$ and $i+1, t_{d b-p l y}$ is the ply thickness of the double-bias material, $m \_d b$ is the minimum number of double-bias plies, and $m$ _ratio is the minimum double-biaslaminate-to-panel-width ratio. The values of $m_{-} d b$ and $m$ ratio are specified by the user (default values are 3 and 0.0025 respectively).

After designing the blade using the criteria described above, we saw the need to increase the laminate thickness in the root area to allow secure attachment of the blade to the hub. A survey of existing blades shows that attachment details vary from one design to another. However, we are able to derive a simple empirical relation to estimate the laminate thickness in the blade root area:

$$
t_{\text {root }}=0.08 \sqrt{\frac{R}{40}} \quad \text { meters }
$$

where $R$ is the rotor radius in meters. This relation is restricted to blade lengths in the range 20 to 80 meters. We are surveying more blades to help us refine this relation and to extend its applicability range. Starting from the root, the thickness obtained from Equation 4 is assumed to be constant over length $l_{\text {const }}$. The thickness then tapers off linearly to thickness $t_{s t r}$ over length $l_{\text {taper }}$, where $t_{s t r}$ is the blade skin thickness determined from the strength criteria. The lengths $l_{\text {const }}$ and $l_{\text {taper }}$ are computed using the following relations based on trend studies:

$$
\begin{aligned}
& l_{\text {const }}=0.51 * d_{\text {root }} \\
& l_{\text {taper }}=0.38 * d_{\text {root }}
\end{aligned}
$$

where $d_{\text {root }}$ is the blade-root diameter. 
Using criteria 1-4 and the numerical approach briefly described in Section 4, we sized the various composite laminates. Our final design requirement is that the thickness of any laminate must be an integer multiple of the ply thickness of the constituent material.

\section{Computation of Structural Properties}

The code offers an option to compute the following structural properties: distributed mass $(m)$, flap stiffness $\left(E I_{\text {flap }}\right)$, lag stiffness $\left(E I_{\text {lag }}\right)$, axial stiffness $(E A)$, torsion rigidity $(G J)$, and offsets of the elasticaxis $(e a)$ and center of mass $(c g)$ from the blade reference axis. Each of these properties is a span-variant section property obtained by integrating the material density or the material elastic parameters distributed over a specific section. The integral relations are quite simple and follow directly from the elementary mechanics of materials [5]. We should mention that the code would overestimate torsion rigidity (GJ), particularly near the blade root region. This occurs because we use the following section integral to compute the torsion rigidity:

$$
G J=\iint_{A} G(\xi, \eta)\left(\xi^{2}+\eta^{2}\right) d \xi d \eta
$$

where $\xi$ and $\eta$ coordinates refer to the elastic principal axes. This relation is consistent with the nonlinear beam theory [5]; and this relation has also been adapted in ADAMS/WT [6]. Consistent with the assumptions made in the rest of the paper, this relation ignores the effect of warping. In the future, we plan to formulate relations that would provide more realistic estimates of $G J$, particularly near the root area.

For computer evaluation of the various integrals that provide the structural properties, we discretize peripherally all the section laminates into a number of area segments. Based on the segment area, its distance and orientation with respect to the $\xi$-and $\eta$-axes, and the elastic moduli of the material enclosed by it, we determine its contribution to a particular section property. The contribution of all material segments is then added to yield the gross section property. When computing blade properties, we include the mass of the nonstructural materials, including gelcoat, nexus, and bonding adhesive. Also, at the blade root section, we take into account the mass contribution of bolts.

\section{Code Usage Steps}

A typical use of the code would be in the preliminary structural design of a blade, followed by its analysis (i.e., computation of properties); this requires seven steps described below. A user may, however, use the code for design alone or for analysis alone by setting the appropriate flags in the input file (we will explain this shortly). The first three steps are the data preparatory steps, wherein the user defines the blade external shape, the properties of the user-selected blade materials, and the extreme bending moment distribution the blade is likely to encounter during its lifetime. As mentioned earlier, this code uses these data in conjunction with the design criteria to size the various composite laminates. The seven steps described below are not intended to be a user's guide; these only highlight the requirements, salient features, limitations, and capabilities of the code (a user's guide will be written following detailed validation studies and a few code refinements). These steps will be exemplified later in Section 7, where we show the application of the code to the design of blades for two- and three-blade rotors.

\section{i) Specification of Blade External Geometry}

The user collects information on the blade's external shape (chord, twist, and airfoil shape variation along the span), which is primarily determined by aerodynamic considerations. This information may come from an aerodynamic design code, for example PROPGA/PROPID [8,9]. Given airfoil shape distribution, these codes generate chord and twist distributions. If computing the properties of an existing blade is the only objective, the user may obtain the shape information from the blade drawings or its tabulated properties. 


\section{ii) Selection of Materials}

The code assumes that the blade would be fabricated by laminating plies of different composite materials. Selection of these materials is an art requiring matching of strength and handling requirements, fabrication process, operating environment, cost considerations, and compatibility of materials. The average user would consult material handbooks, blade manufacturers, and/or material experts. The code requires the user to obtain the following information for each selected material: the ply thickness, the material density, effective Young's modulus in the blade axial (longitudinal) direction, modulus of torsional rigidity about the blade axis, the allowable tensile strength in the axial direction, and the allowable compressive strength in the axial direction (see Table 1 for example).

Table 1: Blade Material Properties

\begin{tabular}{|c|c|c|c|c|c|c|c|}
\hline Material & $\begin{array}{c}\mathbf{t}_{\text {ply }} \\
(\mathbf{m m})\end{array}$ & $\begin{array}{c}\rho \\
\left(\mathbf{K g} / \mathbf{m}^{\mathbf{3}}\right)\end{array}$ & $\begin{array}{c}\mathbf{E} \\
\mathbf{( P a})\end{array}$ & $\begin{array}{c}\mathbf{G} \\
\mathbf{( P a})\end{array}$ & $\begin{array}{c}\sigma_{\mathrm{ut}} \\
\mathbf{( p a )}\end{array}$ & $\begin{array}{c}\sigma_{\mathrm{uc}} \\
\mathbf{( P a )}\end{array}$ & $v$ \\
\hline Gelcoat & 0.381 & 1664 & -- & -- & -- & -- & -- \\
\hline Nexus & 0.51 & 1830 & -- & -- & -- & -- & -- \\
\hline Double-Bias & 0.53 & 1830 & $10.3 \mathrm{E}+9$ & $8.0 \mathrm{E}+9$ & $151 \mathrm{E}+6$ & $-174 \mathrm{E}+6$ & 0.3 \\
\hline Lining & 0.53 & 1830 & $10.3 \mathrm{E}+9$ & $8.0 \mathrm{E}+9$ & $151 \mathrm{E}+6$ & $-174 \mathrm{E}+6$ & 0.3 \\
\hline Unidirectional & 0.53 & 1860 & $37.0 \mathrm{E}+9$ & $4.1 \mathrm{E}+9$ & $986 \mathrm{E}+6$ & $-746 \mathrm{E}+6$ & 0.31 \\
\hline Core & 3.125 & 128.1 & -- & -- & -- & -- & 0.3 \\
\hline
\end{tabular}

\section{iii) Specification of Extreme Load Distribution}

This reflects the extreme bending moment distribution the blade is likely to encounter during its lifetime. In its current phase, the code has no input provision for a time-varying load distribution. Only static load distribution is acceptable; it may, for example, correspond to a once-in-fifty-years hurricane gust impinging on a parked rotor. Knowing the wind conditions, a simple code like YawDyn [10] may be used to generate the extreme load distribution.

\section{iv) Preparation of Main and Auxiliary Input Files}

Following the data collection described above, we prepare input files, which consist of a main input file and a set of auxiliary files. We first describe the main input file (Figure 2). A column has been inserted at the left side of the input file to identify the line numbers; it is not part of the input file. The main input file contains data divided into three blocks: The first block identifies general instructions for the code, the second block identifies material properties, and the third block identifies user-defined design criteria. The header line (the first line of this file) contains user-input text (must be enclosed within quotes as shown) that is directly echoed as a header of the output file; the user may select this text to identify a run or an output file.

The first data block is comprised of lines 5-9. Only the numerical data that appears as the first entry in each line is read by the code; the text to the right of numerical entry in each line is meant only to identify the data entry and is ignored by the code. Numerical data on the fifth line identifies whether the user wants to use the code for design or for analysis. Entry "1" implies design and entry " 2 " implies analysis (i.e., computation of properties). Entry on the next line (" 16 " in this example) identifies the number of 


\begin{tabular}{|c|c|}
\hline Line No. & Input File \\
\hline 1 & 'Design of a hypothetical blade - run id 1234-xyz' \\
\hline 2 & $* * * * * * * * * * * * * * * * *$ main input file $* * * * * * * * * * * * * * * * * * * * * * * * * * * * * * * * * * * * * * * * *$ \\
\hline 3 & 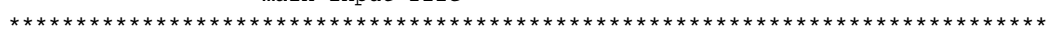 \\
\hline 4 & \\
\hline 5 & objective_id (1=design, $2=$ analysis/properties) \\
\hline 6 & naf (no of airfoils=no of spanwise stations) \\
\hline 7 & output format ( $1=$ std, 2 =adams-compatible, 3 =tabulated output) \\
\hline 8 & blade length \\
\hline 9 & $1 \quad$ blade length scale factor \\
\hline 10 & \\
\hline 11 & \multirow{2}{*}{ 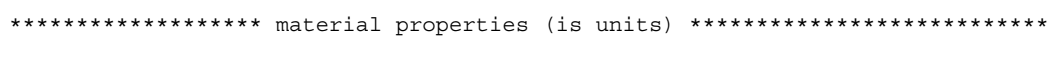 } \\
\hline 12 & \\
\hline 13 & gelcoat properties \\
\hline 14 & 1664 density, rho_gel \\
\hline 15 & 3.81E-04 thickness, tgel \\
\hline 16 & \\
\hline 17 & nexus properties \\
\hline 18 & 0.00051 thickness, tnex \\
\hline 19 & $1.03 \mathrm{E}+10 \quad$ young's modulus, e nex \\
\hline 20 & 8.00E+09 young's modulus, g_nex \\
\hline 21 & 1830 density, rho_nex \\
\hline 22 & \\
\hline 23 & outer skin (double-bias) properties \\
\hline 24 & $0.00053 \quad$ ply thickness (meter), tply_sk \\
\hline 25 & ultimate design stress (tensile), sigt_skin \\
\hline 26 & ultimate design stress (compressive), sigc_skin \\
\hline 27 & young's modulus, e_skin \\
\hline 28 & shear modulus, g_skin \\
\hline 29 & poisson's ratio, anu_sk \\
\hline 30 & density, rho_skin \\
\hline 31 & \\
\hline 32 & boxspar (uni-directional)properties - \\
\hline 33 & $0.00053 \quad$ ply thickness, tply_bx \\
\hline 34 & ultimate design stress (tensile), sigt_box \\
\hline 35 & 3.73E+08 ultimate design stress (compressive), sigc_box \\
\hline 36 & $3.70 E+10 \quad$ young's modulus, e box \\
\hline 37 & shear modulus, g_box \\
\hline 38 & poisson's ratio, anu_bx \\
\hline 39 & density, rho_box \\
\hline 40 & \\
\hline 41 & inner skin (bias_material) properties \\
\hline 42 & $0.00053 \quad$ ply thickness, tply_in \\
\hline 43 & ultimate design stress (tensile), sigt_in \\
\hline 44 & ultimate design stress (compressive), sigc_in \\
\hline 45 & young's modulus, e_in \\
\hline 46 & shear modulus, g_in \\
\hline 47 & poisson's ratio, anu_in \\
\hline 48 & density, rho_in \\
\hline 49 & \\
\hline 50 & core material properties \\
\hline 51 & $3.13 \mathrm{E}-03 \quad$ ply thickness, tply_core \\
\hline 52 & young's modulus (compressive), e_core \\
\hline 53 & poisson's ratio, anu_cr \\
\hline 54 & density, rho_core \\
\hline 55 & \\
\hline 56 & additional mass - $\ldots \ldots-\ldots$ \\
\hline 57 & $40 \quad$ m_inserts (mass of bolts, etc) \\
\hline 58 & \\
\hline 59 & 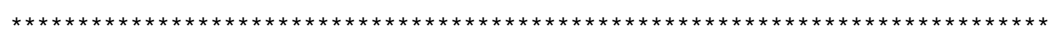 \\
\hline 60 & \\
\hline 61 & design criteria: \\
\hline 62 & \\
\hline 63 & 'min number of skin plies' requirement, min_skpl \\
\hline 64 & 'min t_skin/chord' reqiremnet, min_tsbyc \\
\hline 65 & frac_sk, volume fraction of skin material in root attachment \\
\hline 66 & convergence tolerance for design thickness calculation, tol $t$ \\
\hline 67 & \\
\hline 68 & 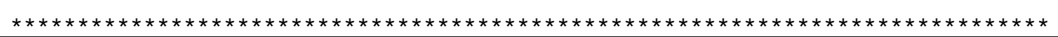 \\
\hline
\end{tabular}

Figure 2. Main input file 
blade span locations at which the user wishes to output the design or analysis results. For each of these stations, the user is required to input span-variant data (e.g., airfoil geometry and bending moment) via auxiliary files (we will explain this shortly). Entry in the seventh line is ignored for a design run; for an analysis run, it identifies how the user wishes to format the structural properties output by the code. A " 1 " directs the code to list properties station-wise; the properties are grouped for each station and are displayed sequentially, starting with the inboard station. Option " 2 " generates an output file that can be directly read by the ADAMS-WT [6] aeroelastic code. Option "3" generates a table of properties that lends itself to easy understanding and plotting. Entry on the eighth line identifies the blade length (not the rotor radius). The last entry in the first data block identifies the blade scale factor; the code uses this factor to scale the blade geometry and the load distribution for a design or analysis run.

Material properties for the gelcoat, the nexus, the double-bias ply, the unidirectional ply, the lining, and the core are entered via the second block. A material property on each line of this block is readily identified by comments on that line. Note that the allowable stress entries are the ultimate stress values divided by a material factor of safety. The last entry is the mass of bolts, which joins the blade to the hub. Later versions of the code will not require this entry (the bolt mass will be computed by the code).

The last data block requires four entries. The first entry is $m+d b$ (the minimum number of double-bias plies), and the second entry is $m_{-}$ratio (the minimum double-bias-laminate-to-panel-width ratio). These two variables are used in Equation 3. The next data entry is the double-bias-to-unidirectional-material volume ratio, which is used to design the blade root reinforcement. The final entry is the thickness tolerance within which the code sizes the various laminates.

Now we describe the auxiliary input files. The number of auxiliary files is identified in the main input file on the seventh line; it is the number of blade span locations at which the user wishes to output the design or analysis results. For each of these stations, the user supplies span-variant input. Figure 3 shows a typical auxiliary input file; all entries in this file refer to a particular blade station. The first data entry is the unidirectional-laminate thickness (for a design run, this value serves as the initial guess for the Newton-Raphson-scheme-based design iterations. Data entries on lines 2-4 represent the skin (doublebias-laminate) thickness, the trailing-edge-cell-core laminate thickness, and the box-core laminate thickness. The code uses these data values only for the analysis run and ignores them for the design run. All the following data are used for both design and analysis runs. Line 5 identifies the span location of the blade station associated for this file. Line 6 represents the chord length, and line 7 represents the flap bending moment at the blade station (the current version of the code does not have a provision for an edgewise bending moment). Line 8 identifies the distance of the blade reference axis from the leading edge, normalized with respect to chord length (the blade built-in twist is defined about this axis; usually it passes through the quarter-chord point for an airfoil section and the mid-chord point for a circular root section). The next line provides the magnitude of the built-in twist (commonly called the aerodynamic twist) of the section chord with respect to the hub plane; it is positive in the feathering direction. Line 10 identifies the number of points on the section periphery that are used to define the airfoil-section geometry. Line 11 provides the number of webs. Line 12 is a blank line. The number of lines in the next block, which are lines 13-73 in the example file, are equal to the number of points used to define the airfoil-section (earlier identified on the tenth line). These lines provide $x$ - and $y$-coordinates of all points defined along the airfoil periphery; these points are defined clockwise along the periphery, starting with the first point $(0,0)$ at the leading edge. The input airfoil coordinates are assumed non-dimensionalized with respect to the blade local chord. The origin of the $(x, y)$ frame is at the leading edge with the $x$-axis directed to the trailing edge and the $y$-axis point toward the upper surface (suction side of the blade section). The next line, line 74 in the example file, is a blank line. The next block of lines, whose number equals the number of webs defined earlier at line 11, identify the end locations for each web. In this example, line 75 identifies the $x-y$ coordinates of the lower and upper ends of the first web, which is the web closest to the leading edge. Line 76 similarly identifies the $x-y$ coordinates of the lower and upper ends of the second and the last web. 


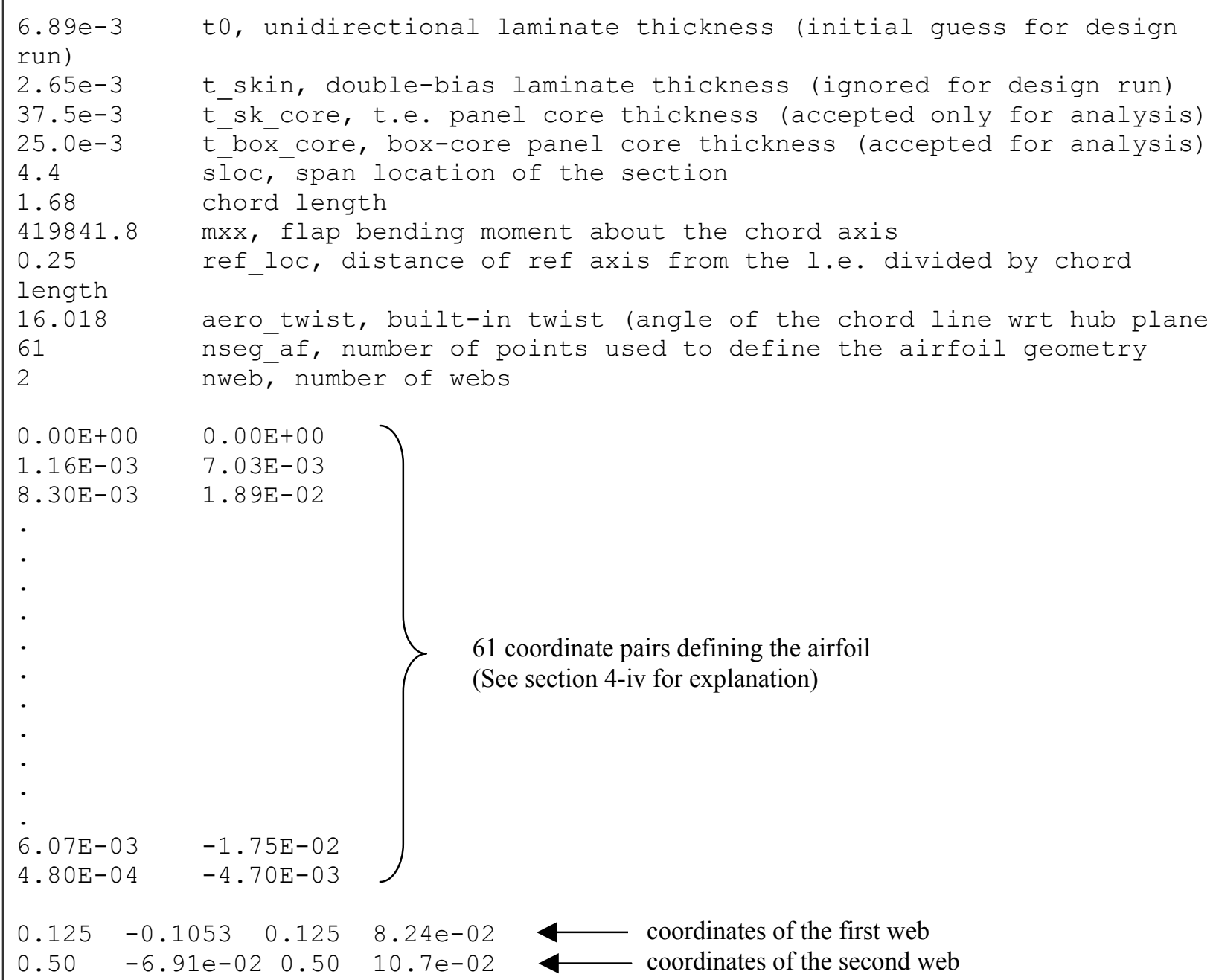

Figure 3: A typical auxiliary input file

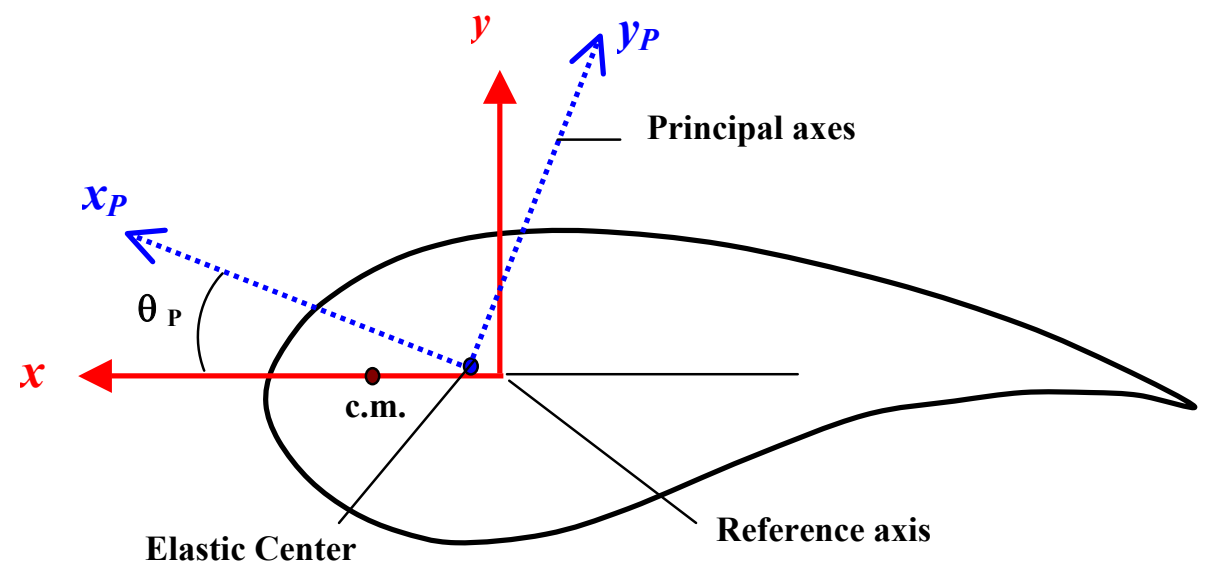

Figure 4: Coordinate systems at a typical blade section 


\section{v) Running the Code for Blade Design}

To design the blade, we execute the code by invoking the design option via the main input file. The objective of the design is to size the thickness of various composite laminates. The design proceeds as follows.

The code uses Equation 3 to compute the double-bias laminate thickness at each user-specified blade section. The computed thickness is then slightly increased to match the nearest integer multiple of the double-bias-ply thickness that is commercially available. Next, to compute the unidirectional and the core laminate thickness, the code analytically expresses the ultimate strength criterion, Equation 1, and the buckling-strength, Equation 2, in terms of the thickness of the load-bearing composite materials. The elastic-center location and the neutral-axis inclination are also expressed analytically in terms of the thickness of the constituent composite materials. Consider Equation 1 first; all quantities in this equation are known except the flexural rigidities $\overline{E I}_{x}, \overline{E I}_{y}$, and $\overline{E I}_{x y}$. To compute these, we discretize the blade section peripherally into a number of area segments. Each area segment consists of a composite laminate. A typical area segment for the blade skin, for example, would include unidirectional plies sandwiched between double-bias plies. Based on the segment elastic modulus, area, and its distance and orientation with respect to the $x$ - and $y$-axes, we determine its contribution to the flexural stiffness. Contribution of all material segments is then added to yield the effective flexural stiffness. The resulting stiffness values are nonlinear functions of the composite materials thickness values, both known and unknown. Note that the $x_{p}$-and $y_{p}$-axes in Figure 4 are the principal axes. The orientation of these axes and the neutral axis location from which these axes originate depend nonlinearly on $\overline{E I}_{x}, \overline{E I}_{y}$, and $\overline{E I}_{x y}$, and are, therefore, also functions of the materials thickness values. Also note that Equation 1 states that the maximum stress over the section should be less than $\sigma_{z z}$. The magnitude of the maximum stress and its location, which is determined by the principal axis location, is a function of the materials thickness (for a non-symmetric airfoil, the maximum stress in general will not occur at the maximum thickness of the airfoil). We set $\sigma_{z z}$ equal to the compressive or tensile allowable design stress value depending on whether the maximum stress is negative or positive.

Equation 2 expresses the buckling criterion. The code applies it to the mid- and trailing-edge panels that are in compression (these are usually the upper-surface panels). The left side of Equation 2 is the panel edge compressive loading and is computed by integrating the axial stresses from the bottom to the top of the panel; the left side of Equation 1 provides the axial stress distribution. The right side integral in Equation 2 depends on the elastic constants $E$ and $v$ of each laminate, including the core material, and its location with respect to the panel's neutral surface. The location of the panel bottom and the neutral surface with respect to the panel top surface depend on the thickness of constituent materials. As a result, both integrals in Equation 2 are nonlinear functions of the material thickness values. These integrals are evaluated via a summation series using the area segments mentioned earlier.

Both Equations 1 and 2 are expressed now in terms of the materials' thicknesses. We apply the NewtonRaphson scheme to solve these nonlinear equations for the unidirectional- and the core-laminate thickness. For a given blade station, two to six iterations usually suffice for computation of these design thickness values within a $10^{-3} \mathrm{~mm}$ tolerance. In the next step, the code uses Equations 4-6 to size the root reinforcement. The iterations required to meet the design criteria are performed automatically within the computer code, and no user interaction is required. Execution time is usually less than one-hundredth of a second.

Finally, we minimally increase the thickness of each composite laminate such that it is an integer multiple of the ply thickness commercially available for that material. The code outputs the design thickness values at all blade stations in a tabulated form (Tables 2 and 3 ). 


\section{vi) Examination/Streamlining of Design}

Usually, the design thickness variation of a particular laminate shows monotonic step drops as we move from the blade root to the tip. For a certain combination of the blade geometry and the load distribution, however, the thickness variation may show intermittent rises, and these may be unacceptable for a real blade. Therefore, we should examine the design output, and if we encounter such rises, we can add a minimal number of extra plies to eliminate the step rises.

\section{vii) Running the Code for Computation of Blade Properties}

Following the blade design described above, a user may be interested in its structural properties. Any wind turbine aeroelastic code (ADAMS [6], FAST [11], or SymDyn [12], for example) would need these properties to build a dynamic model of the rotor. To obtain blade properties, the user first modifies the first four lines of each auxiliary file to reflect the modified thickness values of the unidirectional, doublebias, box-core, and the trailing-edge-core laminates (step vi described above provides the modified values). The user then runs the code using its analysis option. The code outputs the following blade properties along the blade span: distributed mass $(m)$, flap stiffness $\left(E I_{\text {flap }}\right)$, lag stiffness $\left(E I_{\text {lag }}\right)$, axial stiffness $(E A)$, torsion rigidity $(G J)$, and offsets of the elastic-axis $(e a)$ and center of mass (c.m.) from the blade reference axis (Figure 4). As explained in Section 3, these span-variant properties are obtained by integrating the materials' density and elastic parameters over each section. The code offers three options to list the output properties: a section-wise listing, an ADAMS-compatible listing, and a tabulated listing.

As mentioned earlier, the analysis option of the code may be exercised independently; it need not follow the blade design. This may be required, for example, if the user wishes to determine properties of a blade that has already been fabricated or designed. For such a blade, the user obtains the three data sets (described in steps i-iii), either from the blade drawings or from direct measurements. The user enters these data in the main and auxiliary input files and runs the code to estimate the blade properties. 
Table 2. Laminate Thickness Requirements at Various Sections (Blade B2)

\begin{tabular}{|c|c|c|c|c|c|c|c|c|c|c|c|c|c|c|c|c|c|c|}
\hline $\mathrm{rad}$ & chord & $m x x$ & $t d b$ & tdb_n & n_db & tecore & tecore_n & n_tecore & tuni & tuni_n & n_uni & t_midcr & n_midcr & t_le & t_mid & t_te & id_fail & no_iter \\
\hline (m) & (m) & $(k N-m)$ & $(\mathrm{mm})$ & $(\mathrm{mm})$ & & $(\mathrm{mm})$ & $(\mathrm{mm})$ & & $(\mathrm{mm})$ & $(\mathrm{mm})$ & & $(\mathrm{mm})$ & & $(\mathrm{mm})$ & $(\mathrm{mm})$ & $(\mathrm{mm})$ & & \\
\hline 0.00 & 0.83 & 1186.3 & 2.07 & 2.12 & & 0.00 & 0.00 & 0 & 7.59 & 7.95 & 15 & 37.93 & 13 & 3.01 & 51.59 & 3.01 & 1 & 10 \\
\hline 0.48 & 0.83 & 1119.8 & 2.07 & 2.12 & 4 & 0.00 & 0.00 & 0 & 7.13 & 7.42 & 14 & 37.10 & 12 & 3.01 & 47.93 & 3.01 & 1 & 9 \\
\hline 0.55 & 0.83 & 1109.3 & 2.07 & 2.12 & 4 & 0.00 & 0.00 & 0 & 7.06 & 7.42 & 14 & 37.10 & 12 & 3.01 & 47.93 & 3.01 & 1 & 9 \\
\hline 0.67 & 0.83 & 1092.5 & 2.07 & 2.12 & 4 & 0.00 & 0.00 & 0 & 6.94 & 7.42 & 14 & 37.10 & 12 & 3.01 & 47.93 & 3.01 & 1 & 9 \\
\hline 0.79 & 0.83 & 1075.4 & 2.07 & 2.12 & 4 & 0.00 & 0.00 & 0 & 6.82 & 6.89 & 13 & 36.22 & 12 & 3.01 & 47.40 & 3.01 & 1 & 9 \\
\hline 0.80 & 0.83 & 1074.3 & 2.07 & 2.12 & 4 & 0.00 & 0.00 & 0 & 6.82 & 6.89 & 13 & 36.22 & 12 & 3.01 & 47.40 & 3.01 & 1 & 9 \\
\hline 2.30 & 1.55 & 885.8 & 3.87 & 4.24 & 8 & 0.00 & 0.00 & 0 & 3.25 & 3.71 & 7 & 45.50 & 15 & 5.13 & 55.72 & 5.13 & 1 & 7 \\
\hline 4.40 & 2.52 & 640.5 & 3.15 & 3.18 & 6 & 51.02 & 53.13 & 17 & 3.35 & 3.71 & 7 & 29.16 & 10 & 4.07 & 39.03 & 57.20 & 1 & 4 \\
\hline 6.50 & 2.18 & 444.7 & 2.73 & 3.18 & 6 & 43.96 & 46.88 & 15 & 3.17 & 3.18 & 6 & 23.86 & 8 & 4.07 & 32.25 & 50.95 & 1 & 4 \\
\hline 8.60 & 1.87 & 293.3 & 2.34 & 2.65 & 5 & 37.66 & 40.63 & 13 & 3.19 & 3.71 & 7 & 22.35 & 8 & 3.54 & 32.25 & 44.17 & 1 & 4 \\
\hline 10.70 & 1.58 & 180.7 & 1.97 & 2.12 & 4 & 31.81 & 34.38 & 11 & 3.39 & 3.71 & 7 & 20.23 & 7 & 3.01 & 28.60 & 37.39 & 1 & 4 \\
\hline 12.80 & 1.26 & 100.9 & 1.59 & 1.59 & 3 & 25.51 & 28.13 & 9 & 3.63 & 3.71 & 7 & 17.82 & 6 & 2.48 & 24.94 & 30.61 & 1 & 4 \\
\hline 14.90 & 1.01 & 47.3 & 1.59 & 1.59 & 3 & 20.22 & 21.88 & 7 & 3.05 & 3.18 & 6 & 13.07 & 5 & 2.48 & 21.29 & 24.36 & 1 & 4 \\
\hline 17.00 & 0.84 & 14.9 & 1.59 & 1.59 & 3 & 16.69 & 18.75 & 6 & 1.18 & 1.59 & 3 & 8.79 & 3 & 2.48 & 13.45 & 21.23 & 1 & 5 \\
\hline 19.10 & 0.71 & 6.0 & 1.59 & 1.59 & 3 & 14.06 & 15.63 & 5 & 0.42 & 0.53 & 1 & 6.30 & 3 & 2.48 & 12.39 & 18.11 & 1 & 4 \\
\hline 20.15 & 0.56 & 3.0 & 1.59 & 1.59 & 3 & 10.84 & 12.50 & 4 & 0.20 & 0.53 & 1 & 4.69 & 2 & 2.48 & 9.26 & 14.98 & 1 & 5 \\
\hline
\end{tabular}

Design values output by the code

Modified design values

\begin{tabular}{|c|c|c|c|c|c|c|c|}
\hline section & location & tuni-1 & tdb-1 & tuni-2 & tdb-2 & te_core & t_mid_cr \\
\hline & & $(\mathrm{mm})$ & $(\mathrm{mm})$ & $(\mathrm{mm})$ & $(\mathrm{mm})$ & $(\mathrm{mm})$ & $(\mathrm{mm})$ \\
\hline & & & & & & & \\
\hline 2 & 0.00 & 5376 & T.24 & 705 & 50.05 & & \\
\hline 3 & 055 & 4292 & 424 & 795 & 3921 & 000 & 0.00 \\
\hline 4 & 0.67 & 25.58 & 4.24 & 7.95 & 21.87 & 0.00 & 000 \\
\hline 5 & 0.79 & 7.95 & 4.24 & 7.95 & 4.24 & 0.00 & 0.00 \\
\hline 6 & 0.80 & 6.89 & 4.24 & 6.89 & 4.24 & 0.00 & 0.00 \\
\hline 7 & 2.30 & 3.71 & 4.24 & 3.71 & 4.24 & 0.00 & 46.88 \\
\hline 8 & 4.40 & 3.71 & 3.18 & 3.71 & 3.18 & 53.13 & 31.25 \\
\hline 9 & 6.50 & 3.71 & 3.18 & 3.71 & 3.18 & 46.88 & 25.00 \\
\hline 10 & 8.60 & 3.71 & 2.65 & 3.71 & 2.65 & 40.63 & 25.00 \\
\hline 11 & 10.70 & 3.71 & 2.12 & 3.71 & 2.12 & 34.38 & 21.88 \\
\hline 12 & 12.80 & 3.71 & 1.59 & 3.71 & 1.59 & 28.13 & 18.75 \\
\hline 13 & 14.90 & 3.18 & 1.59 & 3.18 & 1.59 & 21.88 & 15.63 \\
\hline 14 & 17.00 & 1.59 & 1.59 & 1.59 & 1.59 & 18.75 & 9.38 \\
\hline 15 & 19.10 & 0.53 & 1.59 & 0.53 & 1.59 & 15.63 & 9.38 \\
\hline 16 & 20.15 & 0.53 & 1.59 & 0.53 & 1.59 & 12.50 & 6.25 \\
\hline
\end{tabular}


Table 3. Laminate Thickness Requirements at Various Sections (Blade B3)

\begin{tabular}{|c|c|c|c|c|c|c|c|c|c|c|c|c|c|c|c|c|c|c|}
\hline $\mathrm{rad}$ & chord & $m x x$ & tdb & tdb_n & n_db & tecore & tecore_n & n_tecore & tuni & tuni_n & n_uni & t_midcr & n_midcr & t_le & t_mid & t_te & id_fail & no_iter \\
\hline (m) & (m) & (kN-m) & $(\mathrm{mm})$ & $(\mathrm{mm})$ & & $(\mathbf{m m})$ & $(\mathrm{mm})$ & & (mm) & $(\mathrm{mm})$ & & $(\mathrm{mm})$ & & $(\mathrm{mm})$ & $(\mathrm{mm})$ & $(\mathrm{mm})$ & & \\
\hline 0.00 & 0.66 & 811.8 & 1.66 & 2.12 & 4 & 0.00 & 0.00 & 0 & 8.27 & 8.48 & 16 & 29.61 & 10 & 3.01 & 42.74 & 3.01 & 1 & 7 \\
\hline 0.48 & 0.66 & 763.2 & 1.66 & 2.12 & 4 & 0.00 & 0.00 & 0 & 7.75 & 7.95 & 15 & 29.09 & 10 & 3.01 & 42.21 & 3.01 & 1 & 7 \\
\hline 0.55 & 0.66 & 755.3 & 1.66 & 2.12 & 4 & 0.00 & 0.00 & 0 & 7.66 & 7.95 & 15 & 29.09 & 10 & 3.01 & 42.21 & 3.01 & 1 & 7 \\
\hline 0.67 & 0.66 & 742.8 & 1.66 & 2.12 & 4 & 0.00 & 0.00 & 0 & 7.53 & 7.95 & 15 & 29.09 & 10 & 3.01 & 42.21 & 3.01 & 1 & 6 \\
\hline 0.79 & 0.66 & 730.2 & 1.66 & 2.12 & 4 & 0.00 & 0.00 & 0 & 7.39 & 7.42 & 14 & 28.53 & 10 & 3.01 & 41.68 & 3.01 & 1 & 6 \\
\hline 0.80 & 0.66 & 729.3 & 1.66 & 2.12 & 4 & 0.00 & 0.00 & 0 & 7.38 & 7.42 & 14 & 28.53 & 10 & 3.01 & 41.68 & 3.01 & 1 & 6 \\
\hline 2.30 & 1.10 & 593.0 & 2.74 & 3.18 & 6 & 0.00 & 0.00 & 0 & 5.01 & 5.30 & 10 & 38.06 & 13 & 4.07 & 50.00 & 4.07 & 1 & 7 \\
\hline 4.40 & 1.68 & 419.8 & 2.10 & 2.12 & 4 & 34.01 & 34.38 & 11 & 5.90 & 6.36 & 12 & 25.63 & 9 & 3.01 & 37.50 & 37.39 & 1 & 8 \\
\hline 6.50 & 1.54 & 284.3 & 1.92 & 2.12 & 4 & 31.05 & 31.25 & 10 & 4.67 & 4.77 & 9 & 21.21 & 7 & 3.01 & 29.66 & 34.26 & 1 & 7 \\
\hline 8.60 & 1.25 & 184.5 & 1.59 & 1.59 & 3 & 25.38 & 28.13 & 9 & 5.10 & 5.30 & 10 & 19.70 & 7 & 2.48 & 29.66 & 30.61 & 1 & 6 \\
\hline 10.70 & 0.99 & 114.1 & 1.59 & 1.59 & 3 & 19.84 & 21.88 & 7 & 6.00 & 6.36 & 12 & 15.06 & 5 & 2.48 & 24.47 & 24.36 & 1 & 5 \\
\hline 12.80 & 0.79 & 65.2 & 1.59 & 1.59 & 3 & 15.65 & 18.75 & 6 & 6.25 & 6.36 & 12 & 10.64 & 4 & 2.48 & 21.34 & 21.23 & 1 & 6 \\
\hline 14.90 & 0.61 & 31.9 & 1.59 & 1.59 & 3 & 11.88 & 12.50 & 4 & 6.14 & 6.36 & 12 & 6.38 & 3 & 2.48 & 18.22 & 14.98 & 1 & 6 \\
\hline 17.00 & 0.46 & 10.6 & 1.59 & 1.59 & 3 & 8.65 & 9.38 & 3 & 3.84 & 4.24 & 8 & 3.95 & 2 & 2.48 & 12.97 & 11.86 & 1 & 7 \\
\hline 19.10 & 0.45 & 2.5 & 1.59 & 1.59 & 3 & 8.63 & 9.38 & 3 & 0.45 & 0.53 & 1 & 3.58 & 2 & 2.48 & 9.26 & 11.86 & 1 & 5 \\
\hline 20.15 & 0.45 & 2.0 & 1.59 & 1.59 & 3 & 8.61 & 9.38 & 3 & 0.22 & 0.53 & 1 & 3.57 & 2 & 2.48 & 9.26 & 11.86 & 1 & 7 \\
\hline
\end{tabular}

Design values output by the code

Modified design values

\begin{tabular}{|c|c|c|c|c|c|c|c|}
\hline section & \multicolumn{1}{c|}{$\begin{array}{l}\text { location } \\
\mathbf{( m )}\end{array}$} & $\begin{array}{c}\text { tuni-1 } \\
\mathbf{( m m})\end{array}$ & $\begin{array}{c}\text { tdb-1 } \\
\mathbf{( m m})\end{array}$ & $\begin{array}{c}\text { tuni-2 } \\
\mathbf{( m m})\end{array}$ & $\begin{array}{c}\text { tdb-2 } \\
\mathbf{( m m})\end{array}$ & $\begin{array}{c}\text { te_core } \\
\mathbf{( m m})\end{array}$ & $\begin{array}{c}\text { t_mid_cr } \\
\mathbf{( m m})\end{array}$ \\
\hline & & & & & & & \\
\hline 1 & 0.00 & 54.82 & 3.18 & 7.42 & 50.58 & 0.00 & 0 \\
\hline 2 & 0.48 & 54.82 & 3.18 & 7.42 & 50.58 & 0.00 & 0 \\
\hline 3 & 0.55 & 43.61 & 3.18 & 7.42 & 39.11 & 0.00 & 0 \\
\hline 4 & 0.67 & 25.66 & 3.18 & 7.42 & 20.77 & 0.00 & 0 \\
\hline 5 & 0.79 & 7.42 & 3.18 & 7.42 & 2.12 & 0.00 & 0 \\
\hline 6 & 0.80 & 7.42 & 3.18 & 7.42 & 2.12 & 0.00 & 0 \\
\hline 7 & 2.30 & 6.36 & 3.18 & 6.36 & 3.18 & 0.00 & 40.625 \\
\hline 8 & 4.40 & 6.36 & 2.12 & 6.36 & 2.12 & 34.38 & 28.125 \\
\hline 9 & 6.50 & 6.36 & 2.12 & 6.36 & 2.12 & 31.25 & 21.875 \\
\hline 10 & 8.60 & 6.36 & 1.59 & 6.36 & 1.59 & 28.13 & 21.875 \\
\hline 11 & 10.70 & 6.36 & 1.59 & 6.36 & 1.59 & 21.88 & 15.625 \\
\hline 12 & 12.80 & 6.36 & 1.59 & 6.36 & 1.59 & 18.75 & 12.5 \\
\hline 13 & 14.90 & 6.36 & 1.59 & 6.36 & 1.59 & 12.50 & 9.375 \\
\hline 14 & 17.00 & 4.24 & 1.59 & 4.24 & 1.59 & 9.38 & 6.25 \\
\hline 15 & 19.10 & 0.53 & 1.59 & 0.53 & 1.59 & 9.38 & 6.25 \\
\hline 16 & 20.15 & 0.53 & 1.59 & 0.53 & 1.59 & 9.38 & 6.25 \\
\hline
\end{tabular}




\section{Code Verification}

We used rectangular, rhombus, circular, and elliptical cross sections of both isotropic and composite materials to verify the code for the ultimate-strength-based design. Code output was compared to exact closed-form calculations for these simple shapes. For the rectangular and rhombus sections, both methods produced virtually identical results. For the circular and elliptical sections, the results were very close. The slight discrepancies, due to the piecewise straight-line discretization of circular and elliptical peripheries, became negligibly small as we refined the discretization. We also used an actual 6-meter-long blade to validate the analysis option of the code. The error between the computed and the actual properties was less than $2 \%$.

For validation of the code for buckling strength design purposes, we used a flat plate subject to known edge loading. An analytical result for this configuration can be readily obtained. Again, we simulated isotropy by inputting the same properties for each ply material. The code prediction exactly matched the analytical result.

A more elaborate validation of the code will be taken up later. We are actively searching for data on actual blades in the 20- to 35-meter length range that is not proprietary and that is sufficiently detailed to allow a meaningful validation of the analysis and the design options of the code. We also plan to validate the code with the help of an ANSYS-built finite-element model of a composite blade.

\section{Results: Design of Blades for Two- and Three-Bladed Rotors}

As mentioned in the introductory section, the code was developed primarily for the structural design of two blades, one for the two-blade rotor and the other for the three-blade rotor. The PROPID code was used for the aerodynamic design, which provided the blade chord and twist distribution. Several performance criteria were exercised that resulted in different external geometries for each blade. Structural design was carried out for each of these geometries. Two designs were finally selected: blade B2 for the two-blade rotor and blade B3 for the three-blade rotor. This section presents results for the two selected blades.

We used the seven steps described in Section 4 to design the blades and to compute their structural properties. For each blade, we began by creating a database for its geometry, material properties, and load distribution. PROPGA and PROPID codes were used to generate the blade chord and twist distributions optimized for minimum cost-of-energy [13]. The airfoil shapes specified for these codes are shown in Figure 5. We assumed each blade to be 20 meters long. Next, to get the load distribution, we selected the IEC Class-2, 50-year extreme wind speed as the design condition. Using this wind condition, the YawDyn code [10] was used to generate the out-of-plane (flap) bending moments. Figures 6a and 6b show the chord, twist, and bending-moment distributions for blades B2 and B3. Each blade has a circular cross section from its root to the 0.8 -meter span location; the diameter is 0.83 meters for blade $\mathrm{B} 2$ and 0.66 meters for blade B3. Thereafter, the blade section transitions into airfoil sections. The blades use NREL S818 (26\% thick), S825 (16\% thick), and S826 (14\% thick) airfoils at 20\%, 70\%, and 90\% rotor span, respectively, with appropriate transitions between these stations. Unlike the chord and twist distributions, the spanwise variation of the airfoil shape is identical for the two blades. The shear webs are located at $12.5 \%$ and $50 \%$ chord for each blade.

The material properties were selected using Reference 14 and other handbooks. Table 1 lists the material properties. Note that the stiffness value of each ply represents its gross value as measured with respect to the blade longitudinal axis; it is not the stiffness value of an individual ply layer with respect to its fiber orientation. The ultimate stresses are the mean values from coupon testing [14]. A safety factor of 2.0 was applied to arrive at the allowable design stresses.

Next, as described in step iv of Section 4, we prepare the main input file (Figure 2). Note that the entry on the third line is " 16 ", which identifies the number of blade span stations at which we wish to output the 
design or analysis results. Span-variant input data at these stations is entered via auxiliary file. We thus have 16 auxiliary input files. Figure 3 shows one of these files; it is for the eighth station of Blade B2. Section 4 provides a physical description of all entries in the main and auxiliary input files.

We now design the blades, starting with blade B2. We run the code using the 16 auxiliary files and the main input file, which lists "1" on its fifth line to invoke the design option. Table 2 shows the output from the design run. The first three columns echo the input radial location, chord length, and bending moment for each of the 16 sections. Other columns list the design thickness of the double-bias, unidirectional, and core-material laminates. The $t d b$, tecore, tuni, and $t$ midcr are the thickness values of the double-bias, trailing-edge-core, unidirectional, and mid-section-core laminates that are directly computed using the design criteria discussed in Section 3. The $t d b \_n$, tecore $n$, and tuni_n are the thickness values updated to satisfy the integer-ply-number criterion. The $n \_d b, n$ tecore, $n \_u n i$, and $n \_$midcr are the number of plies required for the corresponding materials. The numeral " 1 " in the second-to-last column indicates that a double-bias ply fails first; a "2" would imply failure of a unidirectional ply first. The last column shows the number of iterations that the Newton-Raphson scheme uses to compute the design thickness at different stations. As Section 3 describes, we reinforce the blade-root area with additional plies. The total thickness of these plies is dictated by Equation 4, and the spanwise distribution is determined by Equations 5 and 6 . The double-bias and the unidirectional plies would typically be interspersed, and a user can specify the ratio of these plies in the code. For our results, however, we use two extreme cases: a case in which all additional plies utilize double-bias material and a case in which all additional plies utilize unidirectional material. This puts upper and lower bounds on the expected blade properties. Next, following step vi of Section 4, we examine the number of plies in each laminate as we move from the blade root to the tip. We note that this number drops monotonically with one exception: At the 8.6-meter blade span, the number of unidirectional plies jumps from six to seven. To ensure a monotonic drop of plies, we change the number of plies from six to seven over the 6.5- to 8.6-meter blade span. The bottom part of Table 2 lists the design thickness values that account for the additional plies required to reinforce the blade root and to ensure monotonic ply-drop. The tuni- 1 and $t d b-1$ represent thickness of the doublebias and unidirectional laminates when only unidirectional material is used for root reinforcement. The tuni-2 and $t d b-2$ represent these thickness values when only double-bias material is used for root reinforcement. Figures $7 \mathrm{a}-7 \mathrm{~d}$ show the design thickness results graphically. Figure 7a shows the unidirectional and double-bias laminate distributions over the outboard span $(0.8-21.15 \mathrm{~m})$. Figure $7 \mathrm{~b}$ shows the thickness variation of these laminates over the inboard root span for the case when double-bias composite is used for root reinforcement. The $7.95-\mathrm{mm}$ thickness of the unidirectional composite is dictated by the strength criteria, and the double-bias composite thickness variation is dictated by the rootreinforcing requirement. Figure $7 \mathrm{c}$ corresponds to the case when unidirectional composite is used for root reinforcement. Figure $7 \mathrm{~d}$ shows the core-material variation over the full span for the mid- and the trailingedge panels of the blade. Note that no core material is required over the blade-root region.

Table 3 shows the code-generated design output for blade B3. Figure 8 presents these results graphically. A comparison of Figure 8a with Figure 7a shows that the unidirectional material thickness required for blade B3 is higher than that required for blade B2, despite the fact that blade B3 encounters lower aerodynamic loads. This is because blade B3 has lower chord compared to blade B2. And noting that the bending stiffness is roughly proportional to the cube of chord length, thickness of the unidirectional material (which primarily resists the bending loads) must be increased to compensate for loss of stiffness associated with reduced chord.

Next, we used the code to compute the structural properties of the blades. We present results for blade B2 first. Table 4a shows the computer-generated output for the case in which only the double-bias material is used for root reinforcement. Table $4 \mathrm{~b}$ shows the output assuming the use of unidirectional-material root reinforcement. The top parts of the two tables show the variation of blade mass, inertia, stiffness, elasticcenter offset, and mass-centroid offset with respect to the blade span. The bottom parts of the tables provide a weight breakdown of the different materials used in the blade design. The mass of the bolt 
inserts, though shown in the weight breakdown, is not included in section mass distribution. The inserts behave more like a concentrated mass at the discreet root location rather than a distributed mass reflected in the tables. Note that the total blade mass is about the same whether unidirectional- or double-bias material is used for root reinforcement because the two materials have about the same mass density.

Figures 9 and 10 depict the variation of blade B2 properties with span. In Figure 9, we note that over the inboard blade span, the bending and the axial stiffness values are much higher, as expected, if unidirectional material is used for root reinforcement. The torsion stiffness, however, is lower; this is because of the lower shear modulus, $G$, associated with unidirectional material. Note also that the edgewise and torsion stiffness values dip around the 0.8 -meter span location (Figure 9b-c). This is because both of these stiffness values are quite sensitive to the chord length (it is nearly proportional to the cube of the chord). Moving inboard from around the 4-meter location, the chord length reduces and the edgewise and the torsion stiffness values reduce. Inboard of the 0.8 -meter location, the chord is the diameter of a circular section and remains constant, but the root reinforcement contributes substantially to the stiffness values. The slight dips in mass and mass-inertia distribution shown in Figures 10a-b can be interpreted similarly (mass is roughly proportional to chord and mass-inertia is nearly proportional to the cube of the chord).

Table 5 shows spanwise variation of structural properties for blade B3. Table 5a shows results for the case in which only the double-bias material is used for root reinforcement; Table $5 \mathrm{~b}$ shows results when unidirectional material is used for root reinforcement. Again, the top parts of the two tables show the variation of blade mass, inertia, stiffness, elastic-center offset, and mass-centroid offset with respect to the blade span. The bottom parts of the tables provide a weight breakdown of the different materials used in the blade design. As for blade B2, we see that the total blade mass is about the same whether unidirectional- or double-bias material is used for root reinforcement. Note, however, that the total mass of blade B3 is much lower, in the 790-792 $\mathrm{kg}$ range, compared to the mass of blade 2, which is in the $1112-1115 \mathrm{~kg}$ range. Figures 11 and 12 present graphically the variation of blade B3 properties with span. We note that each stiffness or mass property for blade B3 is lower compared to similar property for blade B2; this is expected since blade B3 has a lower chord length all along its span. The trend of properties variation with span, however, is very similar for the two blades. 


\section{Comments and Future Work}

This report presents a computerized method for preliminary design of composite wind turbine blades. It is applicable to blades with arbitrary planform, spanwise airfoil variation, and shear-web placement. The method assumes a specific layout of composite materials within the blade. In principle, it is possible to handle a general layout for the structure, but the code usage would become cumbersome. Therefore, we plan to extend our code to accommodate only a few more layouts popular with designers.

Results show that root reinforcement contributes significantly to blade weight and stiffness. However, we have used only a simple trend-based relation to design this important component. We intend to seek guidance in refining the root design, including bolt attachments, and we also plan to extend the code to accommodate edgewise loading.

For design purposes, the code uses ultimate-strength and static buckling-stability criteria. No stiffness criterion, such as static or dynamic deflection at the blade tip, is used. It would be difficult to accommodate this criterion in an optimal way. Unlike the strength criterion, which may be satisfied independently at each span location, the stiffness criterion requires global analysis of the entire blade. Moreover, dynamic deflections depend on a complex interaction among turbine components and blade aeroelastic feedback. Satisfaction of the stiffness criterion, therefore, requires an aeroelastic model of the entire system in the optimization process. Instead, we assume that an analyst would check blade deflections under extreme operating conditions using an aeroelastic simulation code. If required, the design process may be repeated and material added until computed deflections remain within specified bounds.

Ultimately, we would like to compare our design calculations to data for actual blades. This might identify additional criteria or improvements that need attention.

\section{Acknowledgments}

We thank Kirk Pierce for providing the extreme load distributions and for diligently checking the results and Phillipe Giguere for providing the external geometry of the blades based on his performance optimizations. We appreciate the advice offered by Kip Cheney, Mike Zuteck, and John Mandell, which helped us to arrive at the structural layout and material properties. Finally, we thank Brian Smith for his encouragement and interest throughout this effort. 

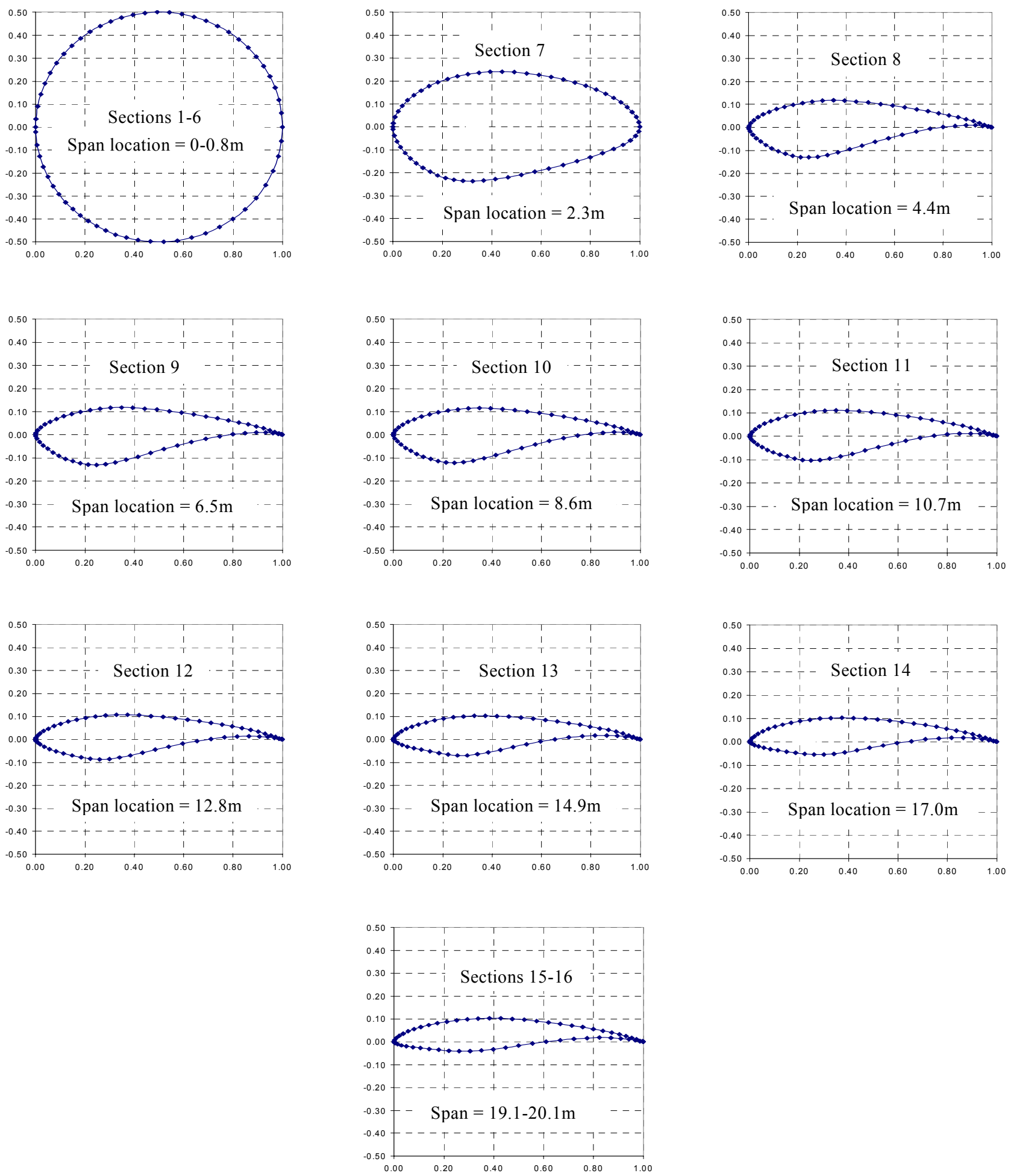

Figure 5: Variation of airfoil geometry along the blade 

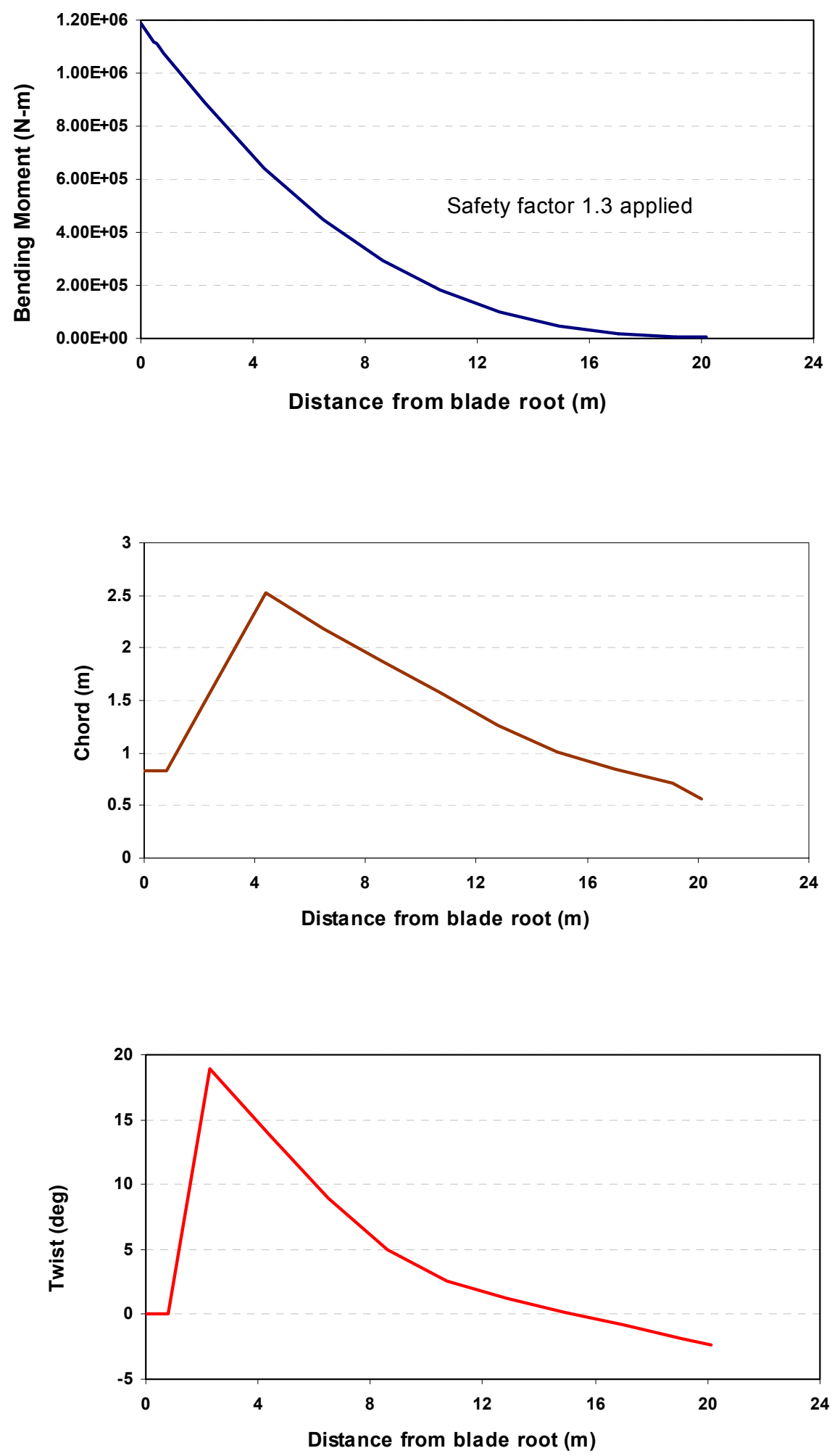

Figure 6a: Bending-moment, chord, and twist distribution along the B2 blade 

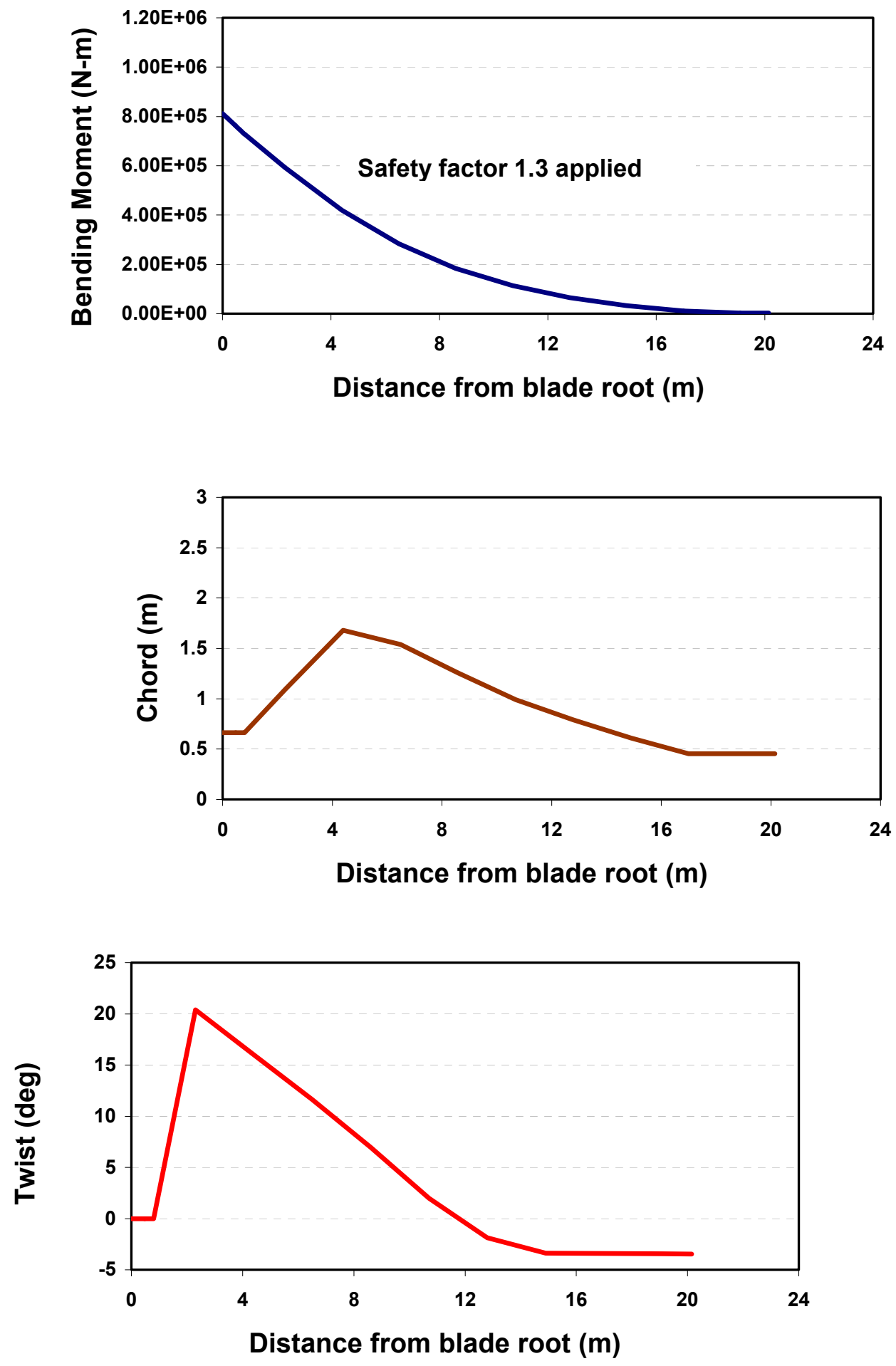

Figure 6b: Bending-moment, chord, and twist distribution along the B3 blade 


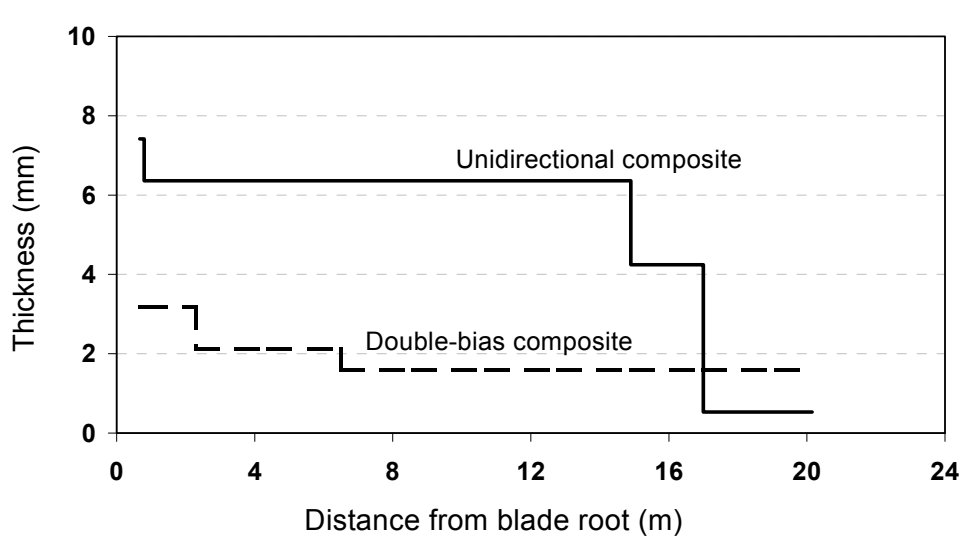

7a) Laminates thickness variation over outboard blade span $(0.8-21.15 m)$

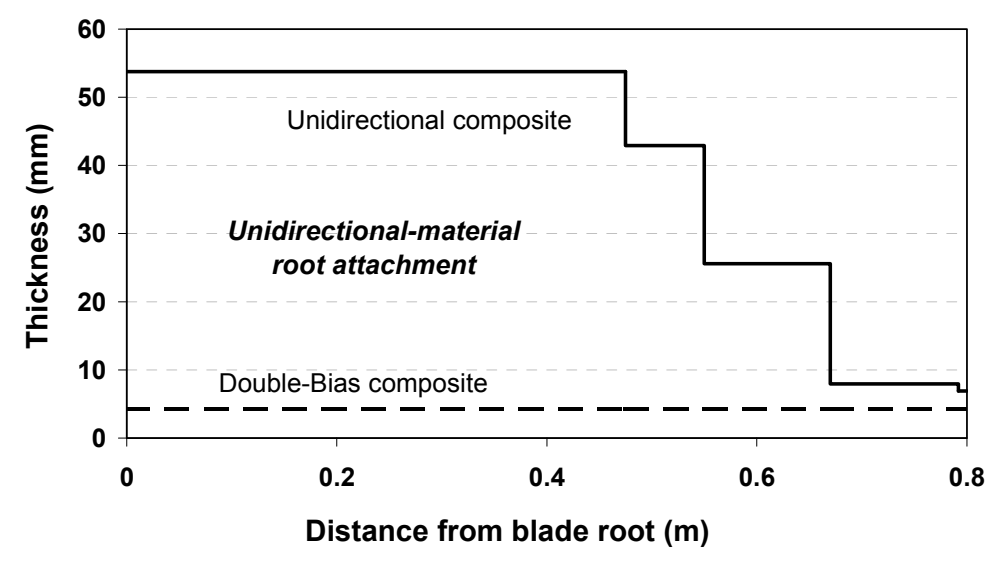

7c) Laminates thickness variation over inboard blade span (unidirectional-material root reinforcement)

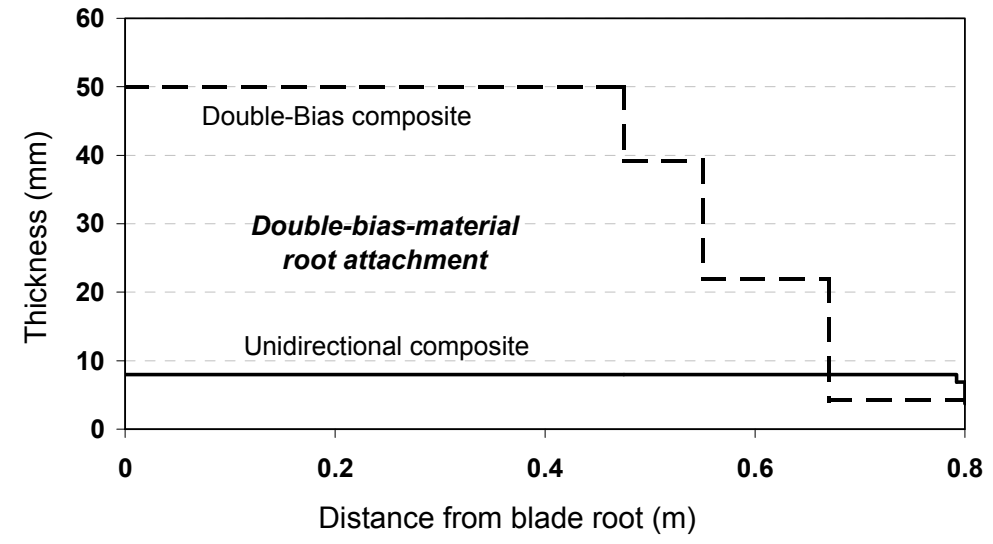

7b) Laminates thickness variation over inboard blade span (double-bias-material root reinforcement)

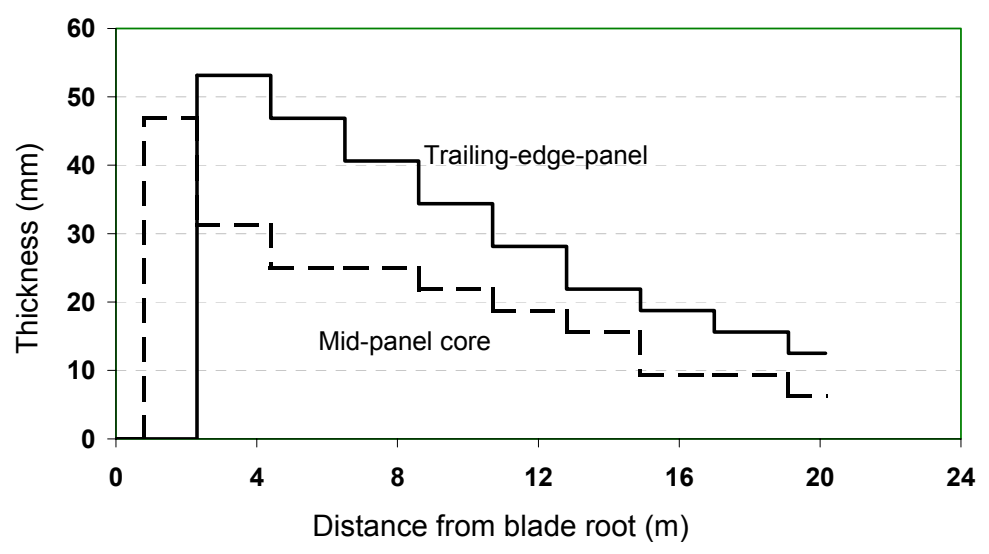

7d) Core-material thickness variation along the blade span

Figure 7: Laminates thickness variation for blade B2 


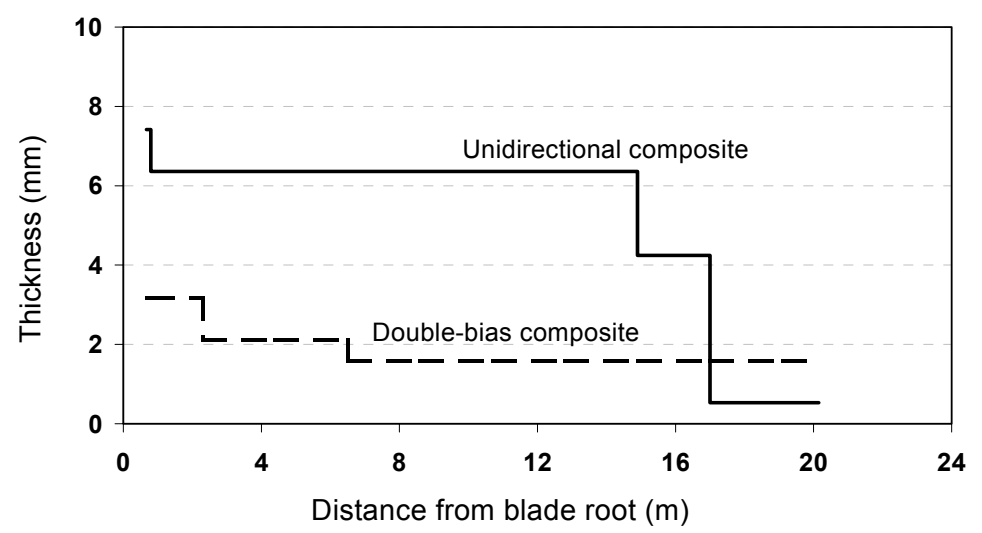

8a) Laminates thickness variation over outboard blade span $(0.8-21.15 m)$

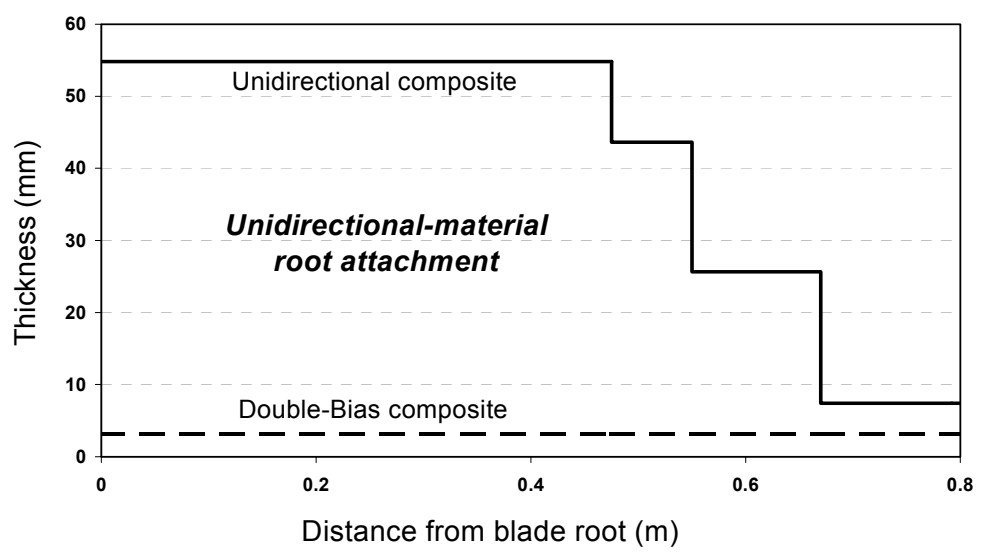

8c) Laminates thickness variation over inboard blade span (unidirectional-material root reinforcement)

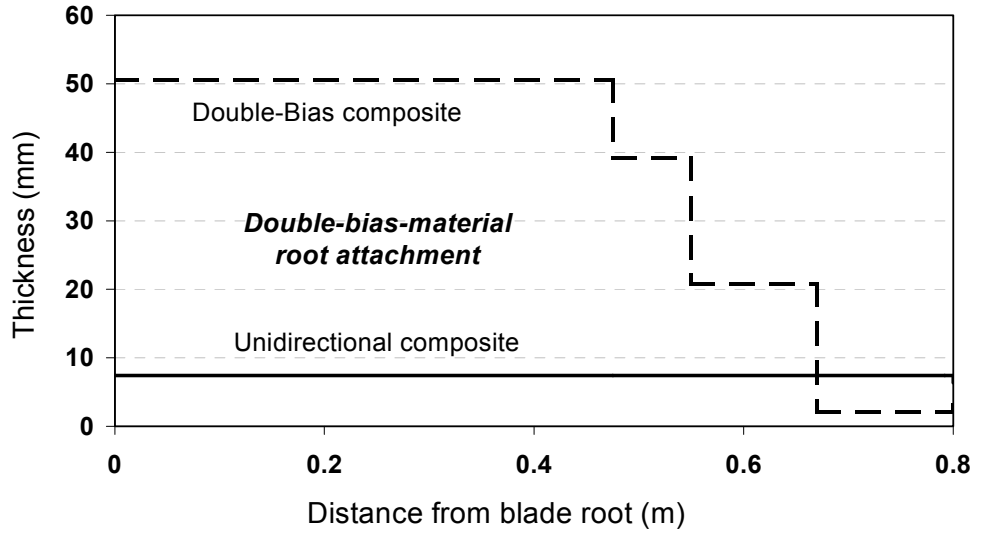

8b) Laminates thickness variation over inboard blade span (double-bias-material root reinforcement)

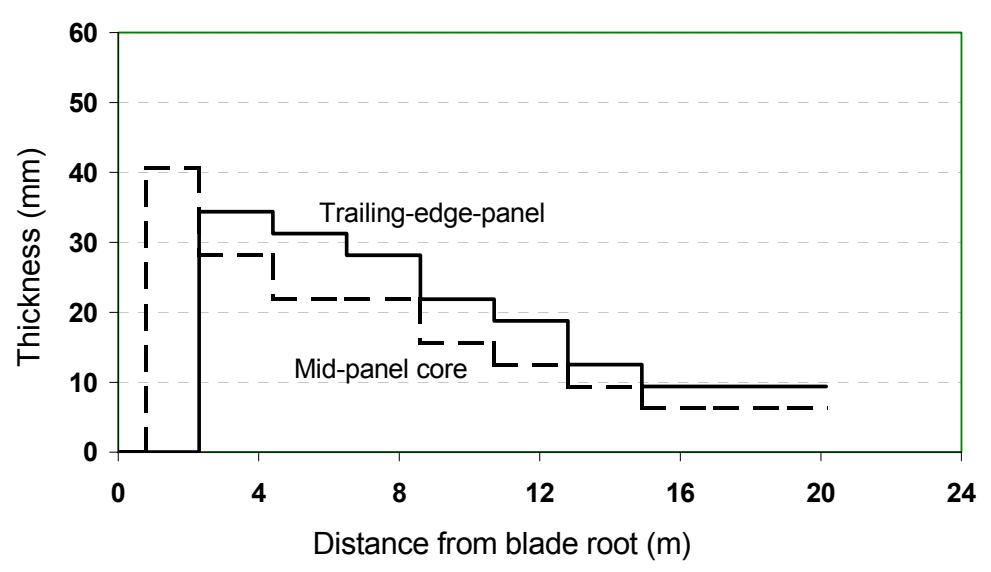

8d) Core-material thickness variation along the blade span

Figure 8: Laminates thickness variation for blade B3 


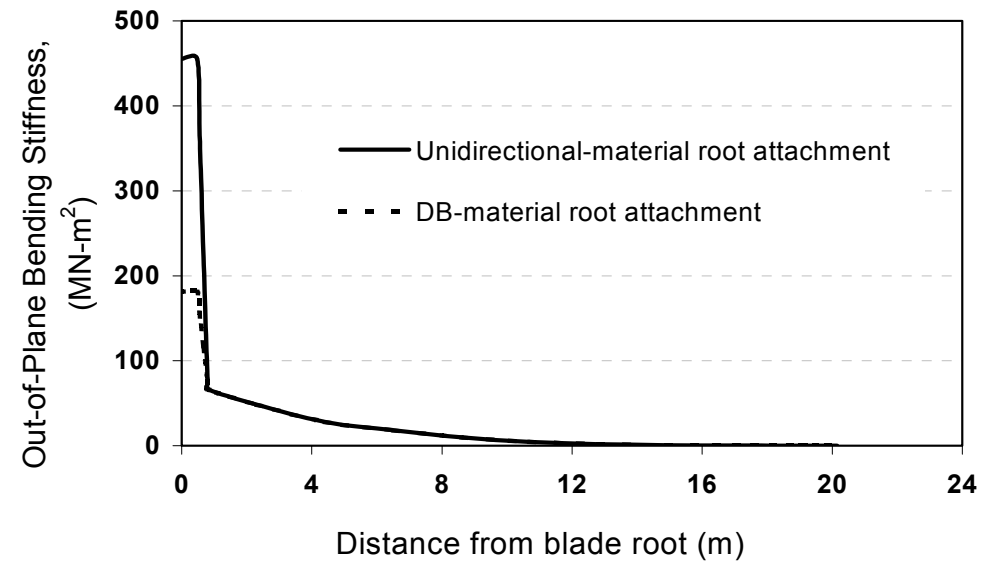

9a) Variation of flap bending stiffness

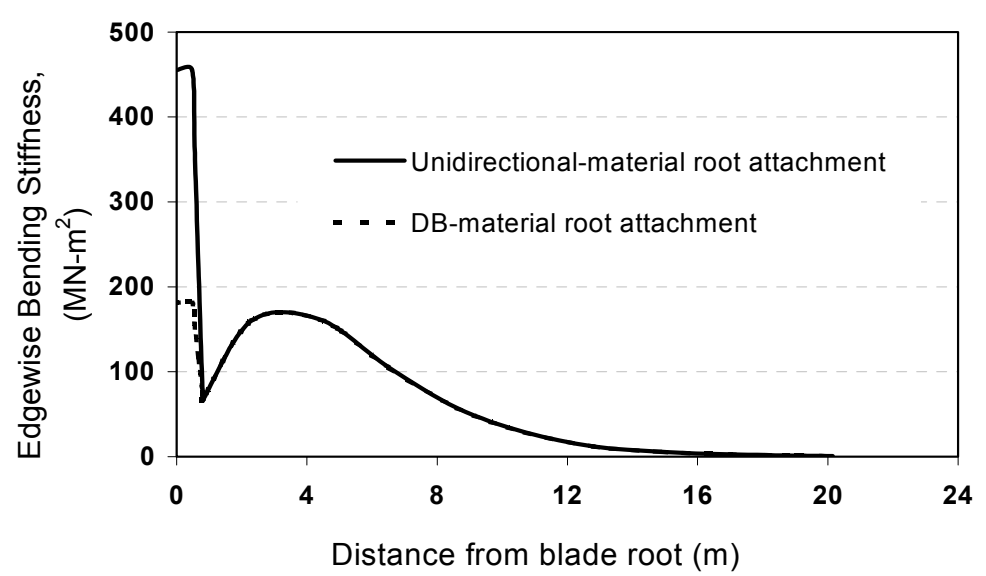

$9 b)$ Variation of edgewise bending stiffness

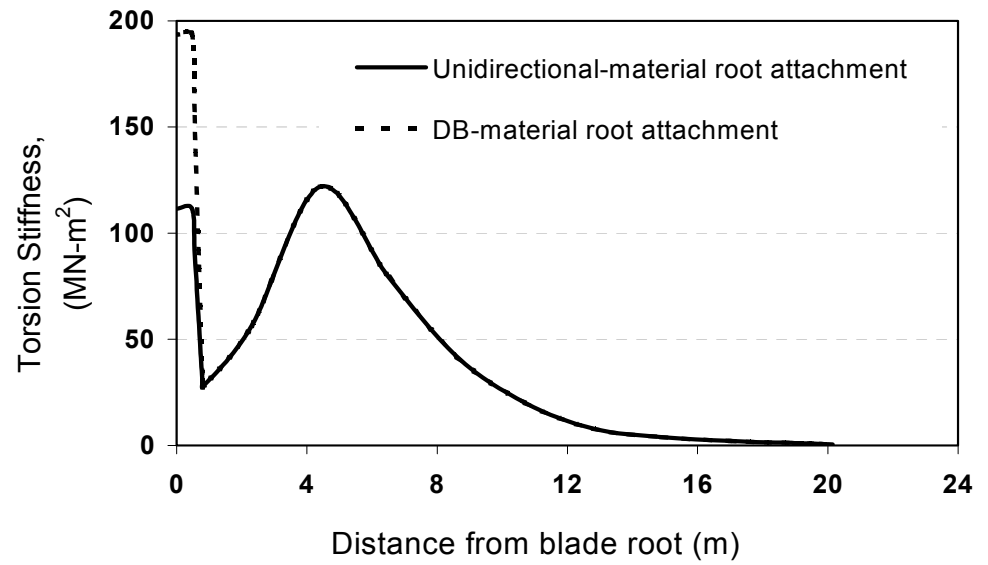

9c) Variation of torsion stiffness

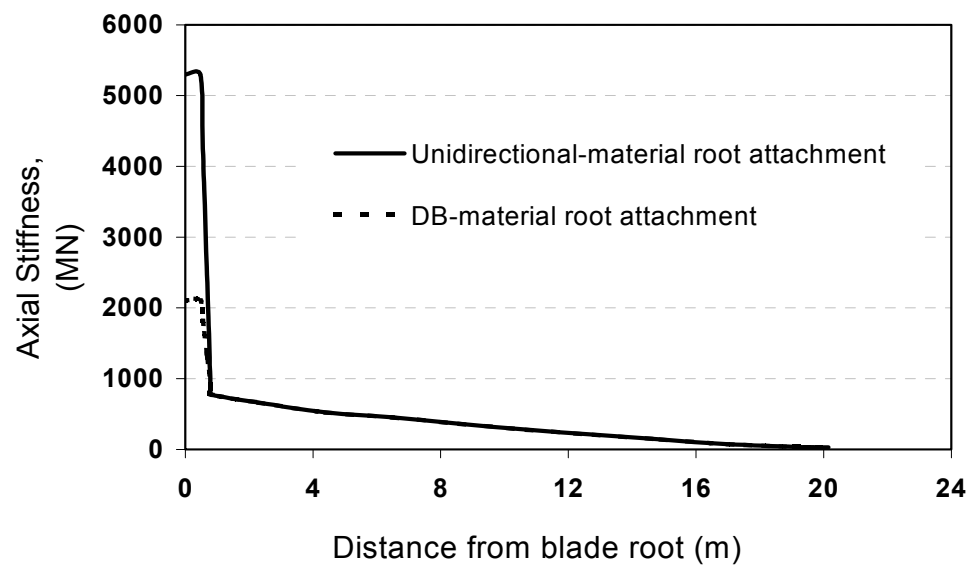

9d) Variation of axial stiffness

Figure 9: Spanwise variation of stiffness properties for blade B2 


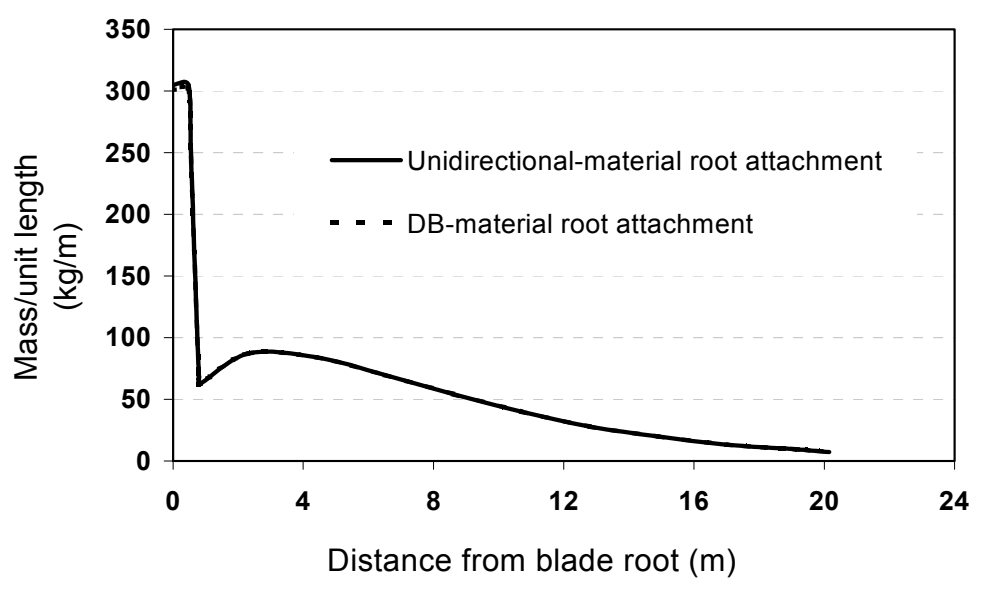

10a) Mass variation along the blade

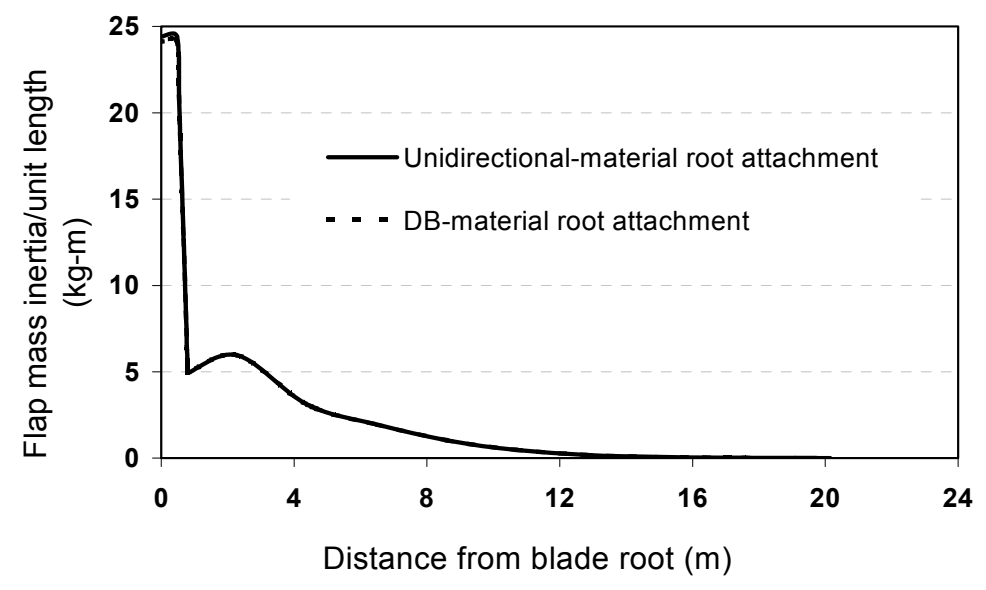

10b) Flap mass inertia variation along the blade

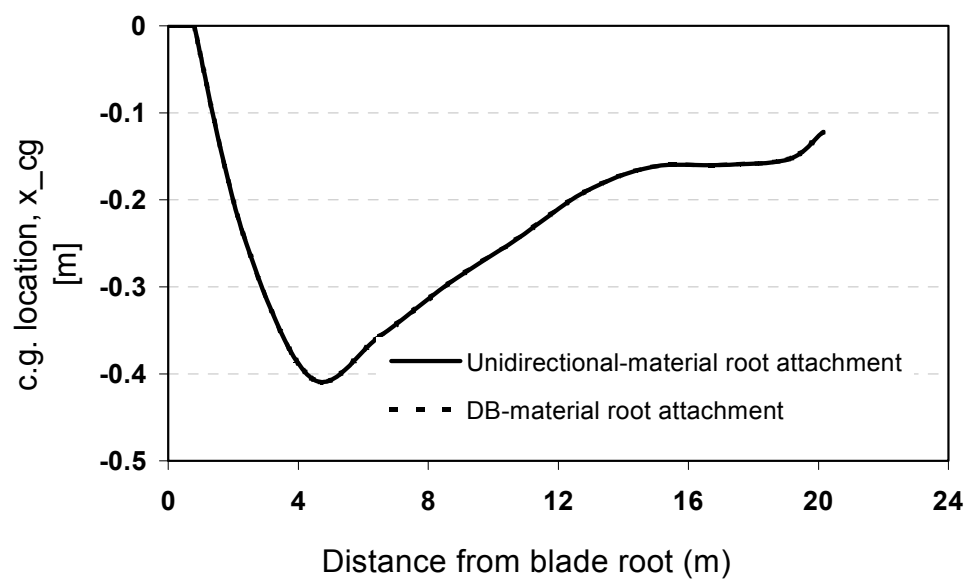

10c) Variation of center-of-mass chordwise location

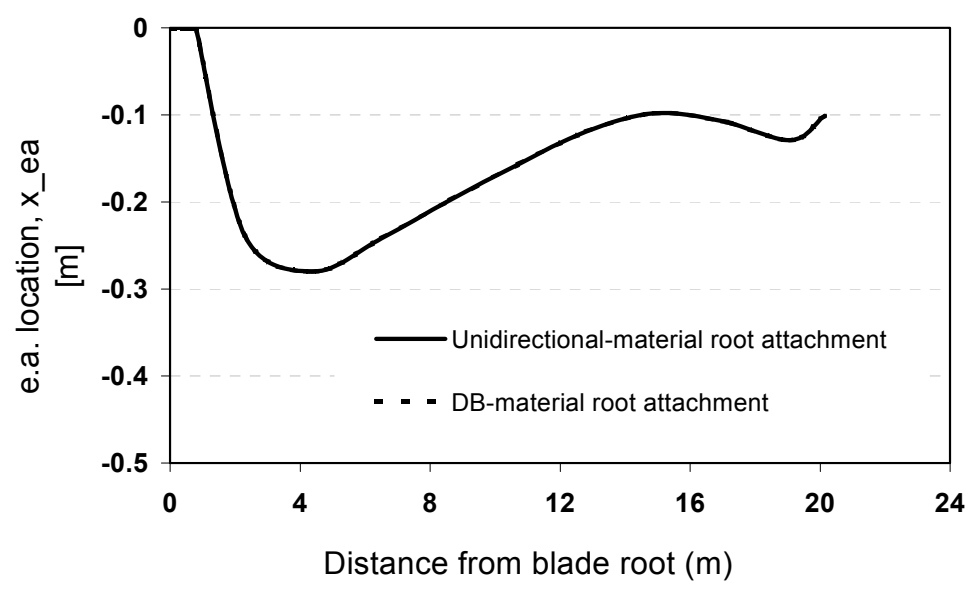

10d) Variation of elastic-axis chordwise location

Figure 10: Variation of section inertia, center-of-mass location, and elastic-axis location along blade B2 


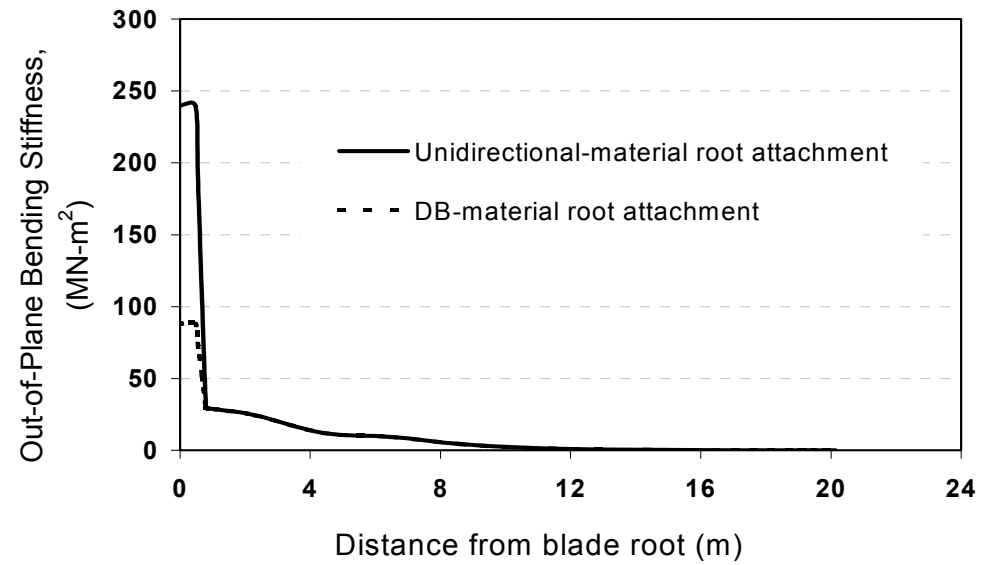

11a) Variation of flap bending stiffness

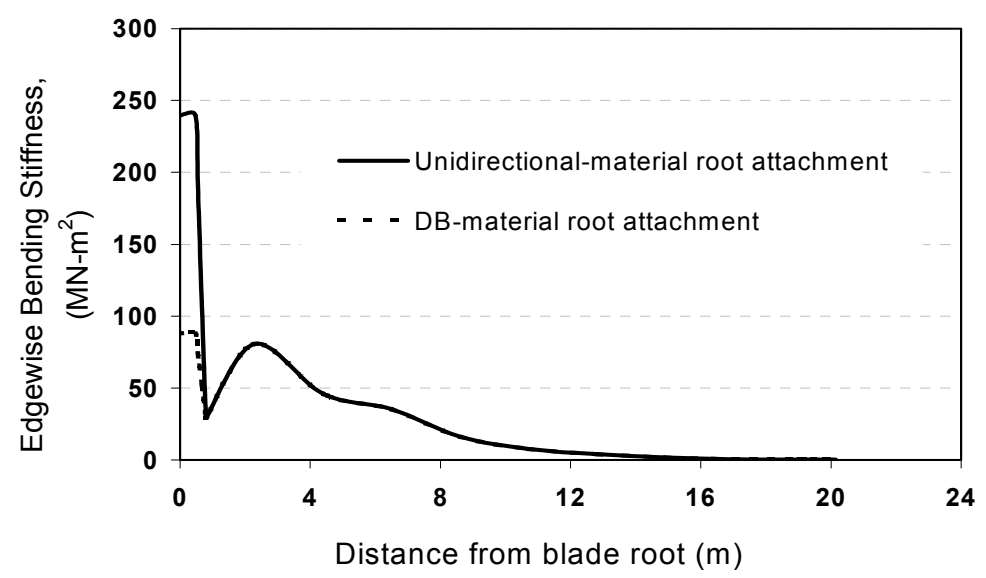

11b) Variation of edgewise bending stiffness

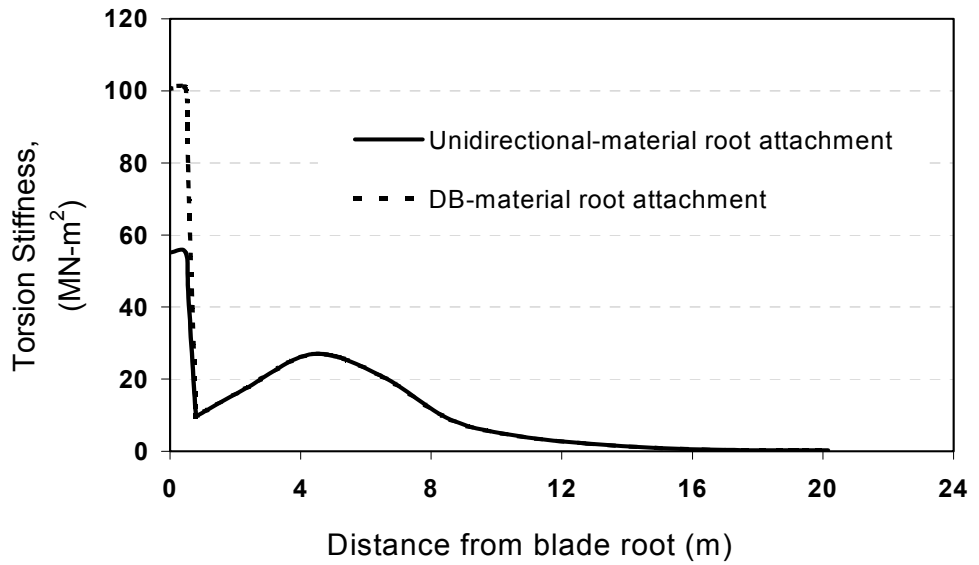

11c) Variation of torsion stiffness

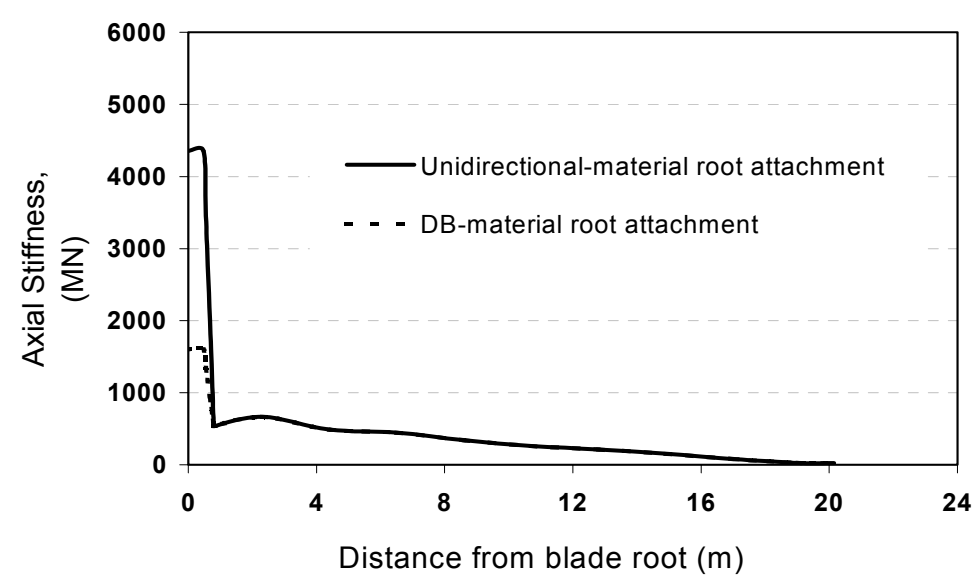

11d) Variation of axial stiffness

Figure 11: Spanwise variation of stiffness properties for blade B3 


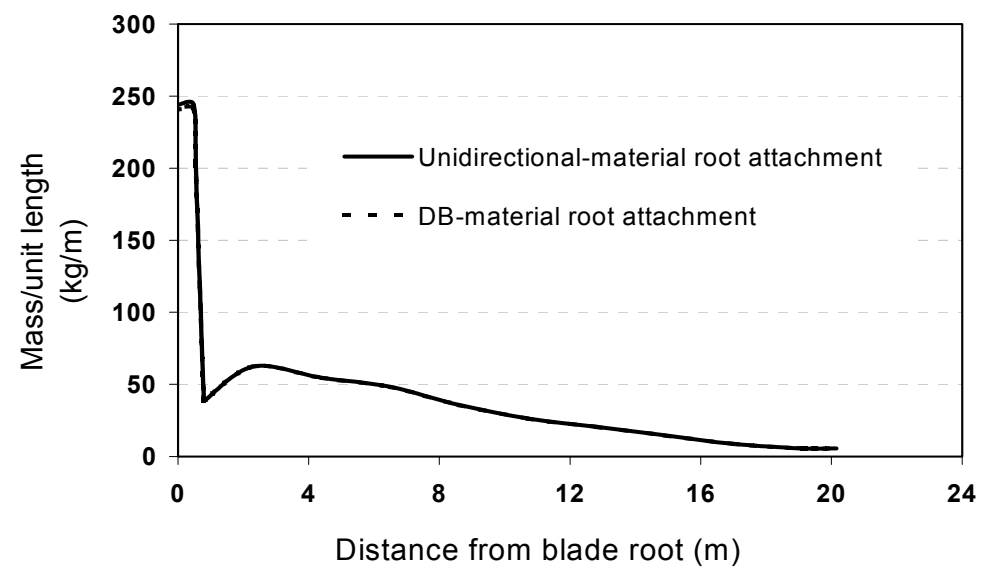

12a) Mass variation along the blade

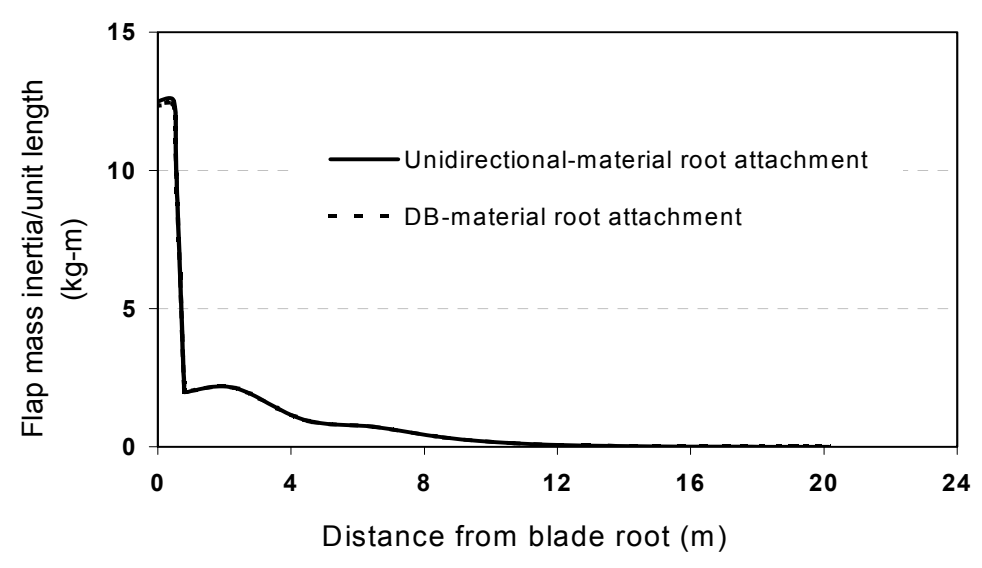

12b) Flap mass inertia variation along the blade

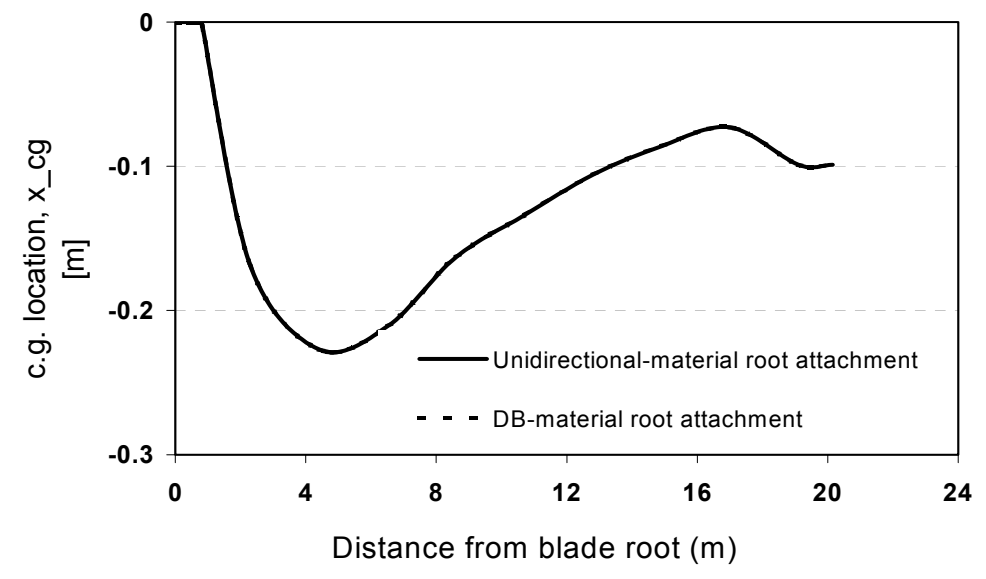

12c) Variation of center-of-mass chordwise location

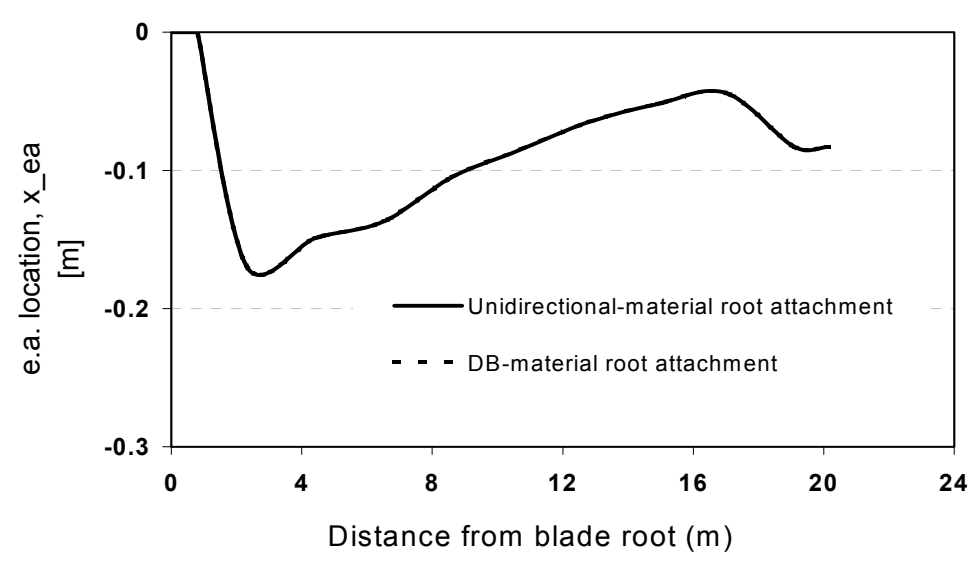

12d) Variation of elastic-axis chordwise location

Figure 12: Variation of section inertia, center-of-mass location, and elastic-axis location along blade B3 
Table 4a. Blade B2 Structural Properties (Double-Bias-Material Root Attachment)

\begin{tabular}{|c|c|c|c|c|c|c|c|c|c|c|c|}
\hline radius & chord & twist & mass & imyy & $\operatorname{imxx}$ & x_cg & x_ea & gj & eaxial & ei_lag & ei_flap \\
\hline (m) & (m) & (deg) & $\mathrm{kg} / \mathrm{m}$ & kg-m & kg-m & (m) & $\overline{(\mathrm{m})}$ & MN-m ${ }^{2}$ & MN & $\mathrm{MN}-\mathrm{m}^{2}$ & $\mathrm{MN}-\mathrm{m}^{2}$ \\
\hline 0.00 & 0.83 & 0.00 & 301.05 & 24.11 & 24.12 & 0.00 & 0.00 & 193.50 & 2109.00 & 181.20 & 181.20 \\
\hline 0.48 & 0.83 & 0.00 & 301.05 & 24.11 & 24.12 & 0.00 & 0.00 & 193.50 & 2109.00 & 181.20 & 181.20 \\
\hline 0.55 & 0.83 & 0.00 & 245.73 & 19.68 & 19.68 & 0.00 & 0.00 & 154.60 & 1818.00 & 156.10 & 156.20 \\
\hline 0.67 & 0.83 & 0.00 & 157.23 & 12.59 & 12.59 & 0.00 & 0.00 & 92.48 & 1353.00 & 116.10 & 116.20 \\
\hline 0.79 & 0.83 & 0.00 & 67.25 & 5.39 & 5.39 & 0.00 & 0.00 & 29.39 & 879.90 & 75.53 & 75.55 \\
\hline 0.80 & 0.83 & 0.00 & 61.75 & 4.95 & 4.95 & 0.00 & 0.00 & 27.49 & 777.80 & 66.76 & 66.78 \\
\hline 2.30 & 1.55 & 18.86 & 87.09 & 19.34 & 5.96 & -0.24 & -0.24 & 56.29 & 662.00 & 160.30 & 48.56 \\
\hline 4.40 & 2.52 & 13.91 & 84.13 & 25.11 & 3.10 & -0.41 & -0.28 & 121.90 & 520.80 & 161.40 & 28.05 \\
\hline 6.50 & 2.18 & 8.95 & 69.84 & 16.26 & 1.95 & -0.36 & -0.24 & 79.34 & 451.30 & 105.10 & 18.26 \\
\hline 8.60 & 1.87 & 4.96 & 54.20 & 9.05 & 1.04 & -0.30 & -0.20 & 41.88 & 362.00 & 57.44 & 10.01 \\
\hline 10.70 & 1.58 & 2.60 & 39.89 & 4.63 & 0.47 & -0.25 & -0.16 & 20.17 & 277.90 & 28.72 & 4.74 \\
\hline 12.80 & 1.26 & 1.25 & 27.87 & 2.00 & 0.18 & -0.19 & -0.12 & 7.88 & 208.10 & 12.15 & 1.90 \\
\hline 14.90 & 1.01 & 0.18 & 19.82 & 0.98 & 0.07 & -0.16 & -0.10 & 3.91 & 141.70 & 5.68 & 0.70 \\
\hline 17.00 & 0.84 & -0.84 & 13.14 & 0.49 & 0.03 & -0.16 & -0.11 & 2.08 & 72.26 & 2.64 & 0.22 \\
\hline 19.10 & 0.71 & -1.86 & 9.50 & 0.27 & 0.01 & -0.15 & -0.13 & 1.10 & 35.66 & 1.29 & 0.07 \\
\hline 20.15 & 0.56 & -2.37 & 7.08 & 0.13 & 0.01 & -0.12 & -0.10 & 0.53 & 27.97 & 0.62 & 0.03 \\
\hline
\end{tabular}

\begin{tabular}{|lrl|}
\hline gelcoat mass & 39.9 & $\mathrm{~kg}$ \\
nexus mass & 58.8 & $\mathrm{~kg}$ \\
core material mass & 193.3 & $\mathrm{~kg}$ \\
+/- 45 mass & 456.6 & $\mathrm{~kg}$ \\
unidirectional mass & 252.8 & $\mathrm{~kg}$ \\
bond material mass & 70.8 & $\mathrm{~kg}$ \\
inserts mass & 40.0 & $\mathrm{~kg}$ \\
total blade mass & $\mathbf{1 1 1 2 . 0}$ & $\mathbf{~ k g}$ \\
\hline
\end{tabular}

Table 4b. Blade B2 Structural Properties (Unidirectional-Material Root Attachment)

\begin{tabular}{|c|c|c|c|c|c|c|c|c|c|c|c|}
\hline radius & chord & twist & mass & imyy & $\operatorname{imxx}$ & x_cg & x_ea & gj & eaxial & ei_lag & ei_flap \\
\hline (m) & (m) & (deg) & $\mathrm{kg} / \mathrm{m}$ & kg-m & kg-m & (m) & (m) & MN-m ${ }^{2}$ & MN & $M \bar{N}-m^{2}$ & $\mathrm{MN}-\mathrm{m}^{2}$ \\
\hline 0.00 & 0.83 & 0.00 & 304.88 & 24.42 & 24.42 & 0.00 & 0.00 & 111.50 & 5295.00 & 455.10 & 455.20 \\
\hline 0.48 & 0.83 & 0.00 & 304.88 & 24.42 & 24.42 & 0.00 & 0.00 & 111.50 & 5295.00 & 455.10 & 455.20 \\
\hline 0.55 & 0.83 & 0.00 & 248.66 & 19.92 & 19.92 & 0.00 & 0.00 & 92.02 & 4250.00 & 365.10 & 365.20 \\
\hline 0.67 & 0.83 & 0.00 & 158.70 & 12.71 & 12.71 & 0.00 & 0.00 & 60.94 & 2579.00 & 221.40 & 221.50 \\
\hline 0.79 & 0.83 & 0.00 & 67.25 & 5.39 & 5.39 & 0.00 & 0.00 & 29.39 & 879.90 & 75.53 & 75.55 \\
\hline 0.80 & 0.83 & 0.00 & 61.75 & 4.95 & 4.95 & 0.00 & 0.00 & 27.49 & 777.80 & 66.76 & 66.78 \\
\hline 2.30 & 1.55 & 18.86 & 87.09 & 19.34 & 5.96 & -0.24 & -0.24 & 56.29 & 662.00 & 160.30 & 48.56 \\
\hline 4.40 & 2.52 & 13.91 & 84.13 & 25.11 & 3.10 & -0.41 & -0.28 & 121.90 & 520.80 & 161.40 & 28.05 \\
\hline 6.50 & 2.18 & 8.95 & 69.84 & 16.26 & 1.95 & -0.36 & -0.24 & 79.34 & 451.30 & 105.10 & 18.26 \\
\hline 8.60 & 1.87 & 4.96 & 54.20 & 9.05 & 1.04 & -0.30 & -0.20 & 41.88 & 362.00 & 57.44 & 10.01 \\
\hline 10.70 & 1.58 & 2.60 & 39.89 & 4.63 & 0.47 & -0.25 & -0.16 & 20.17 & 277.90 & 28.72 & 4.74 \\
\hline 12.80 & 1.26 & 1.25 & 27.87 & 2.00 & 0.18 & -0.19 & -0.12 & 7.88 & 208.10 & 12.15 & 1.90 \\
\hline 14.90 & 1.01 & 0.18 & 19.82 & 0.98 & 0.07 & -0.16 & -0.10 & 3.91 & 141.70 & 5.68 & 0.70 \\
\hline 17.00 & 0.84 & -0.84 & 13.14 & 0.49 & 0.03 & -0.16 & -0.11 & 2.08 & 72.26 & 2.64 & 0.22 \\
\hline 19.10 & 0.71 & -1.86 & 9.50 & 0.27 & 0.01 & -0.15 & -0.13 & 1.10 & 35.66 & 1.29 & 0.07 \\
\hline 20.15 & 0.56 & -2.37 & 7.08 & 0.13 & 0.01 & -0.12 & -0.10 & 0.53 & 27.97 & 0.62 & 0.03 \\
\hline
\end{tabular}

\begin{tabular}{|lrr|}
\hline gelcoat mass & 39.9 & $\mathrm{~kg}$ \\
nexus mass & 58.8 & $\mathrm{~kg}$ \\
core material mass & 193.3 & $\mathrm{~kg}$ \\
+/- 45 mass & 318.3 & $\mathrm{~kg}$ \\
unidirectional mass & 393.4 & $\mathrm{~kg}$ \\
bond material mass & 71.0 & $\mathrm{~kg}$ \\
inserts mass & 40.0 & $\mathrm{~kg}$ \\
total blade mass & $\mathbf{1 1 1 5 . 0}$ & $\mathbf{~ k g}$ \\
\hline
\end{tabular}


Table 5a. Blade B3 Structural Properties (Double-Bias-Material Root Attachment)

\begin{tabular}{|c|c|c|c|c|c|c|c|c|c|c|c|}
\hline radius & chord & twist & mass & imyy & $\operatorname{imxx}$ & x_cg & x_ea & gj & eaxial & ei_lag & ei_flap \\
\hline (m) & (m) & (deg) & $\mathrm{kg} / \mathrm{m}$ & kg-m & kg-m & (m) & (m) & MN-m ${ }^{2}$ & MN & $\mathrm{MN}-\mathrm{m}^{2}$ & $\mathrm{MN}-\mathrm{m}^{2}$ \\
\hline 0.00 & 0.66 & 0.00 & 240.73 & 12.34 & 12.34 & 0.00 & 0.00 & 100.60 & 1599.00 & 87.95 & 87.97 \\
\hline 0.48 & 0.66 & 0.00 & 240.73 & 12.34 & 12.34 & 0.00 & 0.00 & 100.60 & 1599.00 & 87.95 & 87.97 \\
\hline 0.55 & 0.66 & 0.00 & 192.90 & 9.89 & 9.89 & 0.00 & 0.00 & 79.04 & 1347.00 & 74.07 & 74.08 \\
\hline 0.67 & 0.66 & 0.00 & 116.36 & 5.97 & 5.97 & 0.00 & 0.00 & 44.63 & 944.90 & 51.92 & 51.93 \\
\hline 0.79 & 0.66 & 0.00 & 38.55 & 1.98 & 1.98 & 0.00 & 0.00 & 9.71 & 535.90 & 29.44 & 29.44 \\
\hline 0.80 & 0.66 & 0.00 & 38.55 & 1.98 & 1.98 & 0.00 & 0.00 & 9.71 & 535.90 & 29.44 & 29.44 \\
\hline 2.30 & 1.10 & 20.39 & 62.35 & 6.94 & 2.14 & -0.17 & -0.17 & 17.37 & 666.10 & 80.85 & 24.49 \\
\hline 4.40 & 1.68 & 16.02 & 54.56 & 6.56 & 0.98 & -0.23 & -0.15 & 26.95 & 486.50 & 45.89 & 12.12 \\
\hline 6.50 & 1.54 & 11.65 & 48.28 & 5.00 & 0.73 & -0.21 & -0.14 & 20.71 & 445.60 & 35.28 & 9.32 \\
\hline 8.60 & 1.25 & 6.96 & 35.81 & 2.32 & 0.34 & -0.16 & -0.11 & 8.70 & 343.20 & 16.27 & 4.46 \\
\hline 10.70 & 0.99 & 1.98 & 26.30 & 1.11 & 0.13 & -0.13 & -0.09 & 4.17 & 262.40 & 7.69 & 1.82 \\
\hline 12.80 & 0.79 & -1.88 & 20.52 & 0.57 & 0.06 & -0.11 & -0.07 & 2.10 & 211.60 & 3.96 & 0.77 \\
\hline 14.90 & 0.61 & -3.37 & 14.62 & 0.25 & 0.02 & -0.09 & -0.05 & 0.94 & 153.40 & 1.69 & 0.28 \\
\hline 17.00 & 0.46 & -3.41 & 8.73 & 0.09 & 0.01 & -0.07 & -0.04 & 0.37 & 80.07 & 0.57 & 0.07 \\
\hline 19.10 & 0.45 & -3.45 & 5.61 & 0.07 & 0.00 & -0.10 & -0.08 & 0.28 & 22.88 & 0.33 & 0.02 \\
\hline 20.15 & 0.45 & -3.47 & 5.60 & 0.07 & 0.00 & -0.10 & -0.08 & 0.28 & 22.83 & 0.33 & 0.02 \\
\hline
\end{tabular}

\begin{tabular}{|lrl|}
\hline gelcoat mass & 26.7 & $\mathrm{~kg}$ \\
nexus mass & 39.2 & $\mathrm{~kg}$ \\
core material mass & 98.4 & $\mathrm{~kg}$ \\
$+/-45$ mass & 263.4 & $\mathrm{~kg}$ \\
unidirectional mass & 273.1 & $\mathrm{~kg}$ \\
bond material mass & 49.6 & $\mathrm{~kg}$ \\
inserts mass & 40.0 & $\mathrm{~kg}$ \\
total blade mass & 790.4 & $\mathrm{~kg}$ \\
\hline
\end{tabular}

Table 5b. Blade B3 Structural Properties (Unidirectional-Material Root Attachment)

\begin{tabular}{|c|c|c|c|c|c|c|c|c|c|c|c|}
\hline radius & chord & twist & mass & imyy & $\operatorname{imxx}$ & x_cg & x_ea & gj & eaxial & ei_lag & ei_flap \\
\hline (m) & (m) & (deg) & $\mathrm{kg} / \mathrm{m}$ & kg-m & kg-m & (m) & (m) & MN-m ${ }^{2}$ & MN & $\mathrm{MN}-\mathrm{m}^{2}$ & $\mathrm{MN}-\mathrm{m}^{2}$ \\
\hline 0.00 & 0.66 & 0.00 & 244.05 & 12.51 & 12.51 & 0.00 & 0.00 & 55.18 & 4354.00 & 239.70 & 239.80 \\
\hline 0.48 & 0.66 & 0.00 & 244.05 & 12.51 & 12.51 & 0.00 & 0.00 & 55.18 & 4354.00 & 239.70 & 239.80 \\
\hline 0.55 & 0.66 & 0.00 & 195.43 & 10.02 & 10.02 & 0.00 & 0.00 & 44.39 & 3451.00 & 189.80 & 189.90 \\
\hline 0.67 & 0.66 & 0.00 & 117.64 & 6.03 & 6.03 & 0.00 & 0.00 & 27.17 & 2005.00 & 110.20 & 110.20 \\
\hline 0.79 & 0.66 & 0.00 & 38.55 & 1.98 & 1.98 & 0.00 & 0.00 & 9.71 & 535.90 & 29.44 & 29.44 \\
\hline 0.80 & 0.66 & 0.00 & 38.55 & 1.98 & 1.98 & 0.00 & 0.00 & 9.71 & 535.90 & 29.44 & 29.44 \\
\hline 2.30 & 1.10 & 20.39 & 62.35 & 6.94 & 2.14 & -0.17 & -0.17 & 17.37 & 666.10 & 80.85 & 24.49 \\
\hline 4.40 & 1.68 & 16.02 & 54.56 & 6.56 & 0.98 & -0.23 & -0.15 & 26.95 & 486.50 & 45.89 & 12.12 \\
\hline 6.50 & 1.54 & 11.65 & 48.28 & 5.00 & 0.73 & -0.21 & -0.14 & 20.71 & 445.60 & 35.28 & 9.32 \\
\hline 8.60 & 1.25 & 6.96 & 35.81 & 2.32 & 0.34 & -0.16 & -0.11 & 8.70 & 343.20 & 16.27 & 4.46 \\
\hline 10.70 & 0.99 & 1.98 & 26.30 & 1.11 & 0.13 & -0.13 & -0.09 & 4.17 & 262.40 & 7.69 & 1.82 \\
\hline 12.80 & 0.79 & -1.88 & 20.52 & 0.57 & 0.06 & -0.11 & -0.07 & 2.10 & 211.60 & 3.96 & 0.77 \\
\hline 14.90 & 0.61 & -3.37 & 14.62 & 0.25 & 0.02 & -0.09 & -0.05 & 0.94 & 153.40 & 1.69 & 0.28 \\
\hline 17.00 & 0.46 & -3.41 & 8.73 & 0.09 & 0.01 & -0.07 & -0.04 & 0.37 & 80.07 & 0.57 & 0.07 \\
\hline 19.10 & 0.45 & -3.45 & 5.61 & 0.07 & 0.00 & -0.10 & -0.08 & 0.28 & 22.88 & 0.33 & 0.02 \\
\hline 20.15 & 0.45 & -3.47 & 5.60 & 0.07 & 0.00 & -0.10 & -0.08 & 0.28 & 22.83 & 0.33 & 0.02 \\
\hline
\end{tabular}

\begin{tabular}{|lrl|}
\hline gelcoat mass & 26.7 & $\mathrm{~kg}$ \\
nexus mass & 39.2 & $\mathrm{~kg}$ \\
core material mass & 98.4 & $\mathrm{~kg}$ \\
+/- 45 mass & 143.8 & $\mathrm{~kg}$ \\
unidirectional mass & 394.7 & $\mathrm{~kg}$ \\
bond material mass & 49.7 & $\mathrm{~kg}$ \\
inserts mass & 40.0 & $\mathrm{~kg}$ \\
total blade mass & 792.5 & $\mathrm{~kg}$ \\
\hline
\end{tabular}




\section{References}

1. Bir, G.S.; Migliore, P.G. "A Computerized Method for Preliminary Structural Design of Composite Wind Turbine Blades." Proceedings of the AIAA/ASME Wind Energy Symposium, 2001, Paper No. AIAA-2001-0022, pp. 26-37.

2. Laird, D.L. "A Numerical Manufacturing and Design Tool Odyssey." Proceedings of the AIAA/ASME Wind Energy Symposium, 2001, Paper No. AIAA-2001-0023, pp. 20-25.

3. Laird, D.L., 2001, “NuMAD User's Manual,” SAND2001-2375, Sandia National Laboratories Albuquerque, NM.

4. Wind Turbine Generator Systems - Part 1: Safety Requirements; International Standard IEC 6140011, 2nd Edition, 1999-02.

5. Hodges, D.H. and Dowell, E.H., 1974, "Nonlinear Equations of Motion for the Elastic Bending and Torsion of Twisted Nonuniform Rotor Blades," NASA TN D-7818.

6. Elliott, A.S.; Wright, A.D. “ADAMS/WT: An Industry-Specific Interactive Modeling Interface for Wind Turbine Analysis." Wind Energy 1994, Edited by W.D. Musial, S.M. Hock, and D.E. Berg. SED-Vol. 14. New York: American Society of Mechanical Engineers; pp. 111-122.

7. Fu, C.C.; Hsu, Y.T. "The Development of an Improved Curvilinear Thin-Walled Vlasov Element." International Journal of Computer \& Structures, Vol. 54, No. 1, 1994, pp. 147-160.

8. Giguere, P.; Selig, M.S. "Aerodynamic Blade Design Methods for Horizontal Axis Wind Turbines." Canadian Wind Energy Association Conference and Exhibition, Quebec City, Quebec, Canada, October 19-22, 1997.

9. Selig, M.S.; Tangler, J.L. "Development and Application of a Multipoint Inverse Design Method for Horizontal Axis Wind Turbines.” Wind Engineering, Quebec City, Vol. 19, No. 2, 1995, pp. 91-105.

10. Hansen, A.C. "Yaw Dynamics of Horizontal Axis Wind Turbines." Final Report, University of Utah, Salt Lake City, Utah, 1992.

11. Wison, R.E.; Walker, S.N.; Heh, P. 1999. “Technical and User's Manual for the FAST_AD Advanced Dynamic Code.” OSU/NREL Report 99-01, Oregon State University.

12. Stol, K.; Bir, G.S. "Validation of a Symbolic Wind Turbine Structural Dynamics Model." Proceedings of the 19 $9^{\text {th }}$ AIAA/ASME Wind Energy Symposium, Reno, Nevada, 2000, pp. 41-48.

13. Giguere, P. "Aerodynamic Blade Design for a Two-Blade/Two-Speed Rotor: Design Review and Analysis Support for Aerodynamic Design of Rotor Blades in NREL Wind Turbine Development Subcontracts." NREL/NWTC Internal Report, 1999, Golden, CO.

14. Mandell, J.F.; Samborsky, D.D. "DOE/MSU Composite Material Fatigue Database: Test Methods, Materials, and Analysis." SAND97-3002, 1997, Sandia National Laboratories, Albuquerque, NM. 


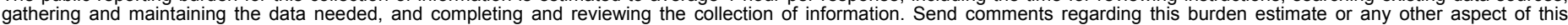

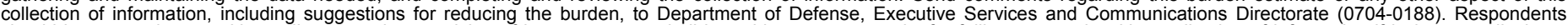

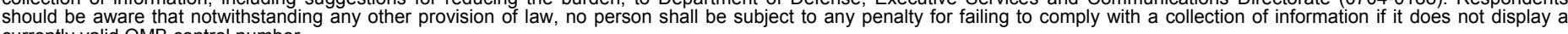

PLEASE DO NOT RETURN YOUR FORM TO THE ABOVE ORGANIZATION.

\begin{tabular}{l|l|l|}
\hline 1. REPORT DATE $(D D-M M-Y Y Y Y)$ & 2. REPORT TYPE & 3. DATES COVERED (FrOm - TO)
\end{tabular} September 2004

Technical Report

4. TITLE AND SUBTITLE

Preliminary Structural Design of Composite Blades for Two- and

Three-Blade Rotors

5a. CONTRACT NUMBER

DE-AC36-99-G010337

5b. GRANT NUMBER

5c. PROGRAM ELEMENT NUMBER

6. AUTHOR(S)

G. Bir; P. Migliore

5d. PROJECT NUMBER

NREL/TP-500-31486

5e. TASK NUMBER

WER4 3303

5f. WORK UNIT NUMBER

7. PERFORMING ORGANIZATION NAME(S) AND ADDRESS(ES)

National Renewable Energy Laboratory

1617 Cole Blvd.

Golden, CO 80401-3393

9. SPONSORING/MONITORING AGENCY NAME(S) AND ADDRESS(ES)

10. SPONSOR/MONITOR'S ACRONYM(S)

NREL

11. SPONSORING/MONITORING

AGENCY REPORT NUMBER

\section{DISTRIBUTION AVAILABILITY STATEMENT}

National Technical Information Service

U.S. Department of Commerce

5285 Port Royal Road

Springfield, VA 22161

13. SUPPLEMENTARY NOTES

14. ABSTRACT (Maximum 200 Words)

A computerized method has been developed to aid in the preliminary design of composite wind turbine blades. The method allows for arbitrary specification of the chord, twist, and airfoil geometry along the blade and an arbitrary number of shear webs. Given the blade external geometry description and its design load distribution, the Fortran code uses ultimate-strength and buckling-resistance criteria to compute the design thickness of load-bearing composite laminates. The code also includes an analysis option to obtain blade properties if a composite laminates schedule is prescribed. These properties include bending stiffness, torsion stiffness, mass, moments of inertia, elastic-axis offset, and center-of-mass offset along the blade. Nonstructural materials-gelcoat, nexus, and bonding adhesive-are also included for computation of mass. The code includes an option to format the output properties that can be directly input to advanced aeroelastic codes. This report summarizes the structural layout of composite laminates within the blade, the design approach, and the computational process. Finally, we present the results of two composite blades designed using this code in support of a project covering comparison of two- and three-blade rotors for a hypothetical turbine.

15. SUBJECT TERMS

wind energy; wind turbine; blades; composite blades; two-blade rotor; three-blade rotor; aeroelastic codes

\begin{tabular}{|l|l|l|l|l|}
\hline \multicolumn{3}{|l|}{ 16. SECURITY CLASSIFICATION OF: } & $\begin{array}{c}\text { 17. } \text { LIMITATION } \\
\text { OF ABSTRACT }\end{array}$ & $\begin{array}{c}\text { 18. } \\
\text { NUMBER } \\
\text { OF PAGES }\end{array}$ \\
\begin{tabular}{|l|l|l} 
a. REPORT \\
Unclassified
\end{tabular} & $\begin{array}{c}\text { b. ABSTRACT } \\
\text { Unclassified }\end{array}$ & $\begin{array}{c}\text { c. THIS PAGE } \\
\text { Unclassified }\end{array}$ & UL &
\end{tabular}

\begin{tabular}{l} 
19a. NAME OF RESPONSIBLE PERSON \\
19b. TELEPONE NUMBER (Include area code) \\
\hline
\end{tabular}

